NBER WORKING PAPER SERIES

\title{
IMPLICATIONS OF LABOR MARKET FRICTIONS FOR RISK AVERSION AND RISK PREMIA
}

Eric T. Swanson

Working Paper 25764

http://www.nber.org/papers/w25764

\author{
NATIONAL BUREAU OF ECONOMIC RESEARCH \\ 1050 Massachusetts Avenue \\ Cambridge, MA 02138 \\ April 2019
}

I thank Andrew Ang, Carol Bertaut, Ian Dew-Becker, Jesús Fernández-Villaverde, Kevin Hasker, Bart Hobijn, SungJun Huh, Ivan Jaccard, Dirk Krueger, Pascal Michaillat, Ayşegül Şahin, and seminar participants at the University of Oslo, Bilkent University, SITE Summer Workshop on Labor and Finance, and Society for Economic Dynamics Meetings for helpful discussions, comments, and suggestions. The views expressed in this paper, and all errors and omissions, should be regarded as those solely of the author, and are not necessarily those of the individuals listed above, nor of the National Bureau of Economic Research.

NBER working papers are circulated for discussion and comment purposes. They have not been peer-reviewed or been subject to the review by the NBER Board of Directors that accompanies official NBER publications.

(C) 2019 by Eric T. Swanson. All rights reserved. Short sections of text, not to exceed two paragraphs, may be quoted without explicit permission provided that full credit, including () notice, is given to the source. 
Implications of Labor Market Frictions for Risk Aversion and Risk Premia

Eric T. Swanson

NBER Working Paper No. 25764

April 2019

JEL No. D81,E24,E44,G12

\begin{abstract}
$\underline{\text { ABSTRACT }}$
A flexible labor margin allows households to absorb shocks to asset values with changes in hours worked as well as changes in consumption. This ability to partially offset wealth shocks by varying hours of work can significantly alter the household's attitudes toward risk, as shown in Swanson (2012). In this paper, I analyze how frictional labor markets affect that analysis. Household risk aversion (as measured by willingness to pay to avoid a wealth shock) is higher: 1) in countries with more frictional labor markets, 2) in recessions, and 3) for households that have more difficulty finding a job. These predictions are consistent with empirical evidence from a variety of sources. Quantitatively, I show that labor market frictions in Europe are large enough to play a substantial contributing role to risk aversion in those countries. Nevertheless, labor markets in the U.S. and Europe are sufficiently flexible that risk aversion is much closer to the frictionless benchmark in Swanson (2012) than to traditional measures that assume labor is fixed.
\end{abstract}

Eric T. Swanson

Department of Economics

University of California at Irvine

3151 Social Science Plaza

Irvine, CA 92697-5100

and NBER

eric.swanson@uci.edu 


\section{Introduction}

A main goal of macro-finance is to bring macroeconomic models into agreement with basic asset pricing facts, such as the equity premium. ${ }^{1}$ In asset pricing, a key parameter is risk aversion, the compensation households require to hold a risky payoff. ${ }^{2}$ At the same time, standard macroeconomic models allow households to vary their labor supply endogenously. A significant challenge in macro-finance research, then, is that traditional studies of risk aversion assume that household labor is exogenously fixed. ${ }^{3}$

Swanson (2012) addresses this problem when households face a frictionless labor market. In the present paper, I re-examine this question in a frictional labor market, as in Mortensen and Pissarides (1994). When the labor market is frictional, the household's ability to partially insure itself from asset value fluctuations by varying hours of work is reduced.

A simple example helps to illustrate the importance of the labor market environment on the household's attitudes toward risk. Suppose that the household has period utility function $u\left(c_{t}, l_{t}\right)=c_{t}^{1-\gamma} /(1-\gamma)-\eta l_{t}$, where $c_{t}$ denotes consumption, $l_{t}$ hours of work, and $\gamma, \eta>0$. If labor $l_{t}$ is exogenously fixed, then the household's coefficient of relative risk aversion is given by the usual $-c u_{11} / u_{1}=\gamma$. However, when labor is flexible and labor markets are frictionless, the household optimally chooses to insure itself from asset value fluctuations by varying hours of work rather than consumption, resulting in a coefficient of relative risk aversion that is zero (Swanson, 2012) - in other words, the household is essentially risk neutral in a frictionless labor market because it optimally varies its labor supply in response to a shock to asset values and is clearly risk-neutral with respect to variations in hours. ${ }^{4}$ When labor markets are frictional rather than frictionless, the household's risk aversion lies somewhere in between these two extremes, because its ability to self-insure lies somewhere in between. In this paper, I ask the interesting question, Where in between these two extremes does household risk aversion lie, and how much

\footnotetext{
${ }^{1}$ For example, Tallarini (2000), Boldrin, Christiano, and Fisher (2001), Uhlig (2007), Backus, Routledge, and Zin (2008), Rudebusch and Swanson (2008, 2012), Van Binsbergen et al. (2012), Palomino (2012), Andreasen (2012a,b), Gourio (2012, 2013), Ai, Croce, and Li (2013), Croce (2014), Dew-Becker (2014), Kung (2015), Ai, Croce, Diercks, and Li (2018), and Swanson (2019) all consider asset pricing in dynamic macroeconomic models with a variable labor margin.

${ }^{2}$ Throughout this paper, I define a household's coefficient of (absolute or relative) risk aversion in terms of its willingness to pay to avoid a wealth gamble. See Section 1.1 and Section 3, below for additonal discussion.

${ }^{3}$ For example, Arrow (1965) and Pratt (1964) define absolute and relative risk aversion, $-u^{\prime \prime}(c) / u^{\prime}(c)$ and $-c u^{\prime \prime}(c) / u^{\prime}(c)$, in a static model with a single consumption good (and no labor).

${ }^{4}$ This example is extreme, due to the linearity of hours in the household's preferences. More generally, when $u\left(c_{t}, l_{t}\right)=c_{t}^{1-\gamma} /(1-\gamma)-\eta l_{t}^{1+\chi} /(1+\chi)$, Swanson $(2012)$ shows that risk aversion is given by $\left(\gamma^{-1}+\chi^{-1}\right)^{-1}$ a combination of the parameters on the consumption and labor margins, reflecting that the household absorbs shocks to asset values along both margins.
} 
does risk aversion vary for different levels of labor market frictions?

To answer this question, I derive closed-form expressions for risk aversion when labor markets are frictional rather than fixed (the traditional case) or frictionless (as in Swanson, 2012). I show how these closed-form expressions depend on the ratio of labor market flow rates to the household's discount rate. Intuitively, labor market frictions only delay, and do not prevent, the household's labor adjustment; thus, higher flow rates or a lower discount rate imply that frictions are less of a concern to the household because this delay is either shorter or less costly.

The closed-form expressions for risk aversion I derive here have three main implications: First, risk aversion is higher for households in more frictional labor markets (e.g., Continental Europe). Second, risk aversion is higher in recessions, when unemployment is higher and it is more difficult to adjust employment. Third, risk aversion is higher for households that are less likely to find jobs (e.g., retirees, the less educated, and households suffering from discrimination). In all of these cases, it is more difficult for the household to vary its hours in response to shocks, and so more of the burden of asset fluctuations passes through to consumption.

These model predictions are consistent with empirical evidence from a variety of sources. Guiso, Haliassos, and Jappelli (2002) and Ynesta (2008) document that the portfolio holdings of European households are substantially more conservative than those of U.S. households, consistent with the first prediction. Consistent with the second prediction, Guiso, Sapienza, and Zingales (2017) show that survey estimates of household risk aversion increased substantially during the 2008-09 recession. Moreover, Fama and French (1989), Cooper and Priestley (2009), and others show that risk premia on stocks, bonds, and other financial assets tend to be higher in recessions. ${ }^{5}$ Consistent with the third prediction, the portfolios of households near retirement are more conservative than those of younger households (Guiso et al., 2002). Although some of these empirical observations may be driven by other factors as well, differences in labor market frictions may play an important contributing role.

I investigate the quantitative importance of these predictions by calibrating the model's parameters to the U.S. and several European countries. For the U.S., labor market flow rates are sufficiently high that risk aversion is virtually the same as in the frictionless benchmark (Swanson, 2012), both in expansions and recessions. For European countries, differences in labor market frictions can play a significant role in cross-country differences in relative risk aversion,

\footnotetext{
${ }^{5}$ See also Campbell and Cochrane (1999), Campbell (1999), Lettau and Ludvigson (2010), Piazzesi and Swanson (2008), and Cochrane and Piazzesi (2005).
} 
accounting for up to a $35 \%$ increase. I show that labor market frictions could play an important role in cyclical variability in risk aversion in these countries as well. However, even in these countries, labor markets are flexible enough that risk aversion is much closer to the frictionless benchmark in Swanson (2012) than to traditional measures that assume labor is fixed.

These quantitative estimates are conservative, because the only cost of labor market frictions in the model is the cost of delayed labor adjustment, which is completely characterized by the household's discount rate $r$. To the extent that labor market frictions impose additional costs on households through borrowing constraints, depreciation of human capital, or stigma associated with longer spells of unemployment, the costs of labor market frictions will effectively increase $r$ in the model and lead to larger effects.

\subsection{Related Literature}

Arrow (1965) and Pratt (1964) define absolute and relative risk aversion, $-u^{\prime \prime}(c) / u^{\prime}(c)$ and $-c u^{\prime \prime}(c) / u^{\prime}(c)$, as the household's willingness to pay to avoid a fair gamble over a single good in a one-period model. Subsequent authors have generalized this definition to the case of multiple goods in two different ways. The first approach, which I follow in this paper, is to measure the household's willingness to pay to avoid a fair gamble over money or wealth. ${ }^{6}$ This approach is also taken by Stiglitz (1969) in a static model with multiple goods, and by Constantinides (1990) and Campbell and Cochrane (1999) in a dynamic model with a single good (where consumption in the different periods represent multiple goods). As shown in Swanson (2012) and in Section 3, below, this money- or wealth-based definition implies that the household's coefficient of risk aversion is determined by the curvature of its indirect utility function (in a static model) or value function (in a dynamic model). ${ }^{7}$

The alternative approach to defining risk aversion over multiple goods is taken by Kihlstrom and Mirman $(1974,1981)$, who define a household's attitudes toward risk in a multi-dimensional way that depends only on its preferences and its total consumption bundle. Thus, other features of the household's environment that affect its value function but not its preferences do not affect the household's attitudes toward risk in this approach. Moreover, the household's attitudes toward

\footnotetext{
${ }^{6}$ Both Arrow (1965) and Pratt (1964) explicitly worked with a "utility function for money" (Pratt, 1964, p. 122) or wealth: "Let $Y=$ wealth, $U(Y)=$ total utility of wealth $Y$ " (Arrow, 1965, pp. 91-92), and defined risk aversion in terms of a fair gamble over money or wealth.

${ }^{7}$ See also Epstein, Farhi, and Strzalecki (2014), who consider a household's willingness to pay to resolve uncertainty sooner rather than later (what they call the "timing premium"). As they show, this willingness to pay also depends on the household's value function.
} 
risk are multi-dimensional and cannot be summarized by a single "coefficient of risk aversion" except in very special cases, such as when the household's preferences are homothetic (Kihlstrom and Mirman, 1981).

Throughout this paper, I use the first definition of "risk aversion" above, and not the second. That is, I define a household's coefficient of risk aversion, below, in terms of its willingness to pay to avoid an idiosyncratic wealth gamble. This definition has several advantages for asset pricing: for example, a household's aversion to a wealth gamble is always well-defined under the technical conditions I impose below (e.g., twice-differentiability) and is closely related to the household's willingness to hold a risky asset. The alternative, multi-dimensional, Kihlstrom-Mirman (1974, 1981) definition does not have a single coefficient of risk aversion in general and doesn't provide insight into how much compensation a household would require to hold a risky asset, except in very special cases such as homothetic preferences. ${ }^{8}$

Empirically, there is substantial evidence that households vary their labor supply in response to financial shocks. Imbens, Rubin, and Sacerdote (2001) and Cesarini, Lundqvist, Notowidigdo, and Östling (2017) show that households who win even a moderately-sized lottery prize reduce their hours of work significantly. Cesarini et al. (2017) show that this adjustment takes place on the intensive as well as extensive margin, and for spouses of lottery winners as well as winners themselves. Coronado and Perozek (2003) show that households retire earlier after the stock market performs well, while Coile and Levine (2009) find that households are less likely to retire after the stock market performs poorly. Pencavel (1986) and Killingsworth and Heckman (1986) provide early surveys of the wealth effect on labor supply and find it to be significantly negative.

A recent paper by Petrosky-Nadeau, Zhang, and Kuehn (2018) shows that labor market frictions can generate rare consumption disasters and a higher equity premium. In their model, labor supply (the sum of workers plus job searchers) is exogenously fixed, so the traditional, fixed-labor measure of risk aversion is appropriate. In the present paper, I show how labor market frictions interact with flexible labor supply to alter the household's attitudes toward risk. ${ }^{9} \mathrm{My}$ analysis doesn't rely on rare disasters and instead focuses on the model's behavior near the steady state, although numerical results can be obtained farther away from the steady state as well.

The remainder of the paper proceeds as follows. In Section 2, I define a general dynamic

\footnotetext{
${ }^{8}$ If the household has homothetic preferences and is unconstrained, then there exists a Kihlstrom-Mirman scalar coefficient of risk aversion which, in fact, agrees with the willingness to pay definition that I use in this paper (Kihlstrom and Mirman, 1974, Section 3.1). In this sense, the two definitions agree.

${ }^{9}$ Many macroeconomic models with labor market frictions allow labor supply to be flexible, such as Merz (1995), Andolfatto (1996), Trigari (2009), and Shimer (2010).
} 
equilibrium framework with labor market frictions. In Section 3, I derive closed-form expressions for risk aversion in that framework and present a numerical example showing the importance of the labor margin. In Section 4, I derive the three implications of labor market frictions for risk aversion described above. I explore the quantitative importance of these results in Section 5. Section 6 concludes. An Appendix provides details of the model, proofs, and numerical solution methods that are outlined in the main text.

\section{Dynamic Equilibrium Framework with Labor Market Frictions}

\subsection{The Household's Optimization Problem and Value Function}

Time is discrete and continues forever. At each time $t$, the household seeks to maximize the expected present discounted value of utility flows,

$$
E_{t} \sum_{\tau=t}^{\infty} \beta^{\tau-t}\left[U\left(c_{\tau}\right)-V\left(l_{\tau}+u_{\tau}\right)\right]
$$

where $E_{t}$ denotes the mathematical expectation conditional on the household's information set at time $t, \beta \in(0,1)$ is the discount factor, and $c_{\tau}, l_{\tau}$, and $u_{\tau}$ denote the household's state-contingent plans for future consumption, labor, and unemployment at time $\tau$. The explicit state-dependence of these plans is suppressed to reduce notation. In contrast to Swanson (2012), period utility in (1) is assumed to be additively separable in order to make the analysis of labor market frictions tractable. Let $\Omega_{c}$ denote the domain of $c_{\tau}$ and $\Omega_{l u}$ the set of possible values for $l_{\tau}+u_{\tau}$.

Assumption 1. The function $U: \Omega_{c} \rightarrow \mathbb{R}$ is increasing, twice-differentiable, and strictly concave, and $V: \Omega_{l u} \rightarrow \mathbb{R}$ is increasing, twice-differentiable, and strictly convex.

A detailed microfoundation for the household's preferences in (1) is tangential to the present discussion, but is provided in the Appendix. Briefly, the household consists of a unit continuum of individuals who pool their income. At each time $t$, an individual who is not employed can either search for a job or stay home and produce nonmarket goods and services (including "leisure"). The household's home production function is increasing and concave in the number of individuals staying at home; as a result, $V$ in (1) is increasing and convex in the number of workers not at home, $l_{t}+u_{t}{ }^{10}$

\footnotetext{
10 The labor market search literature often assumes that household leisure or home production is linear in the number of workers staying at home (e.g., Shimer, 2010). Assumption 1 requires strict convexity of $V$ in order to guarantee the uniqueness of the household's optimal choice of $\left(c_{t}, u_{t}\right)$ at each time $t$, discussed below. Intuitively, the case of a linear $V$ can be approximated with a $V$ having infinitesimal convexity.
} 
The labor market is characterized by search and matching. Household labor $l_{t}$ is a state variable rather than a choice variable, evolving according to

$$
l_{t+1}=(1-s) l_{t}+f\left(\Theta_{t}\right) u_{t},
$$

where $s \in[0,1]$ denotes a constant exogenous rate of job destruction, $\Theta_{t} \in \Omega_{\Theta}$ is a Markovian state vector that is exogenous to the household and characterizes the state of the aggregate economy at time $t$, and $f: \Omega_{\Theta} \rightarrow[0,1]$ is a function of the aggregate state that gives the measure of jobs found per unit of unemployed workers searching for a job.

In each period $t$, the household chooses $c_{t}$ and $u_{t}$ (and a state-contingent plan for future $c_{\tau}$ and $u_{\tau}$ ) to maximize (1), subject to the labor market friction (2), the flow budget constraint

$$
a_{t+1}=\left(1+r_{t}\right) a_{t}+w_{t} l_{t}+d_{t}-c_{t}
$$

and the no-Ponzi condition

$$
\lim _{T \rightarrow \infty} E_{t} \prod_{\tau=t}^{T}\left(1+r_{\tau+1}\right)^{-1} a_{T+1} \geq 0
$$

where $a_{t}$ denotes the household's beginning-of-period assets and $w_{t}, r_{t}$, and $d_{t}$ denote the real wage, real interest rate, and real net transfer payments to the household in each period $t$, respectively.

The exogenous Markov state vector $\Theta_{t}$ governs the processes for $w_{t}, r_{t}$, and $d_{t}$. Before choosing $c_{t}$ and $u_{t}$ in each period, the household observes $\Theta_{t}$ and hence $w_{t}, r_{t}$, and $d_{t} \cdot{ }^{11}$ The household's information set and state vector at each date $t$ is thus $\left(a_{t}, l_{t} ; \Theta_{t}\right)$, where $a_{t}$ and $l_{t}$ are endogenous and $\Theta_{t}$ is exogenous to the household. Let $X$ denote the domain of $\left(a_{t}, l_{t} ; \Theta_{t}\right), \Omega$ the domain of $\left(c_{t}, u_{t}\right)$, and $\Gamma: X \rightarrow \Omega$ the set-valued correspondence of feasible choices for $\left(c_{t}, u_{t}\right)$ for each given $\left(a_{t}, l_{t} ; \Theta_{t}\right)$.

In addition to Assumption 1, a few more technical conditions are required to ensure the value function for the household's optimization problem exists, satisfies the Bellman equation, and is unique, continuous, and concave. The details of these conditions are tangential to the present paper (see Stokey and Lucas (1990), Alvarez and Stokey (1998), and Rincón-Zapatera

\footnotetext{
$11_{\text {Thus, }} r_{t}$ is known to the household at time $t$. However, $a_{t}$ denotes the household's beginning-of-period assets and is a state variable, so the household cannot change $a_{t}$ in period $t$. If the household saves in period $t$, then that increases $a_{t+1}$ and earns the return $r_{t+1}$ in the next period. Thus, the return to saving in period $t$ is $r_{t+1}$, which can be either known (risk-free) or unknown (risky) to the household at time $t$.
} 
and Rodríguez-Palmero (2003) for different sets of such sufficient conditions), so I simply assume that:

Assumption 2. There exists a solution $\mathbb{V}: X \rightarrow \mathbb{R}$ to the household's Bellman equation,

$$
\mathbb{V}\left(a_{t}, l_{t} ; \Theta_{t}\right)=\max _{\left(c_{t}, u_{t}\right) \in \Gamma\left(a_{t}, l_{t} ; \Theta_{t}\right)} U\left(c_{t}\right)-V\left(l_{t}+u_{t}\right)+\beta E_{t} \mathbb{V}\left(a_{t+1}, l_{t+1} ; \Theta_{t+1}\right)
$$

where $l_{t+1}$ is given by (2) and $a_{t+1}$ by (3), and the function $\mathbb{V}$ is unique, continuous, and concave.

The same technical conditions, together with Assumption 1, guarantee a unique optimal choice for $\left(c_{t}, u_{t}\right)$ at each point in time, given $\left(a_{t}, l_{t} ; \Theta_{t}\right)$. Let $c_{t}^{*} \equiv c^{*}\left(a_{t}, l_{t} ; \Theta_{t}\right)$ and $u_{t}^{*} \equiv$ $u^{*}\left(a_{t}, l_{t} ; \Theta_{t}\right)$ denote these optimal choices as functions of the state $\left(a_{t}, l_{t} ; \Theta_{t}\right)$. Then

$$
\mathbb{V}\left(a_{t}, l_{t} ; \Theta_{t}\right)=U\left(c_{t}^{*}\right)-V\left(l_{t}+u_{t}^{*}\right)+\beta E_{t} \mathbb{V}\left(a_{t+1}^{*}, l_{t+1}^{*} ; \Theta_{t+1}\right)
$$

where $a_{t+1}^{*} \equiv\left(1+r_{t}\right) a_{t}+w_{t} l_{t}+d_{t}-c_{t}^{*}$ and $l_{t+1}^{*} \equiv(1-s) l_{t}+f\left(\Theta_{t}\right) u_{t}^{*}$. To avoid boundary solutions for $c_{t}^{*}$ and $u_{t}^{*}$, I require that these solutions be interior:

Assumption 3. For any $\left(a_{t}, l_{t} ; \Theta_{t}\right) \in X$, the household's optimal choice $\left(c_{t}^{*}, u_{t}^{*}\right)$ exists, is unique, and lies in the interior of $\Gamma\left(a_{t}, l_{t} ; \Theta_{t}\right)$.

Intuitively, Assumption 3 requires that $U$ and $V$ satisfy Inada-type boundary conditions. ${ }^{12}$

Assumptions 1-3 imply that $\mathbb{V}$ is continuously differentiable with respect to $a$, but in order to define risk aversion below, I require slightly more than this:

Assumption 4. For any $\left(a_{t}, l_{t} ; \Theta_{t}\right)$ in the interior of $X$, the second derivatives of $\mathbb{V}$ with respect to its first two arguments, $\mathbb{V}_{11}\left(a_{t}, l_{t} ; \Theta_{t}\right), \mathbb{V}_{12}\left(a_{t}, l_{t} ; \Theta_{t}\right)$, and $\mathbb{V}_{22}\left(a_{t}, l_{t} ; \Theta_{t}\right)$, exist.

Santos (1991) provides sufficient conditions for Assumption 4 to be satisfied; intuitively, $U$ and $V$ must be strongly concave. Note that Assumption 4 also implies that the policy functions, $c^{*}$ and $u^{*}$, are differentiable with respect to $a_{t}$ and $l_{t}$.

\subsection{Representative Household and Steady State Assumptions}

The analysis so far considers a single household in isolation, leaving the rest of the economy unspecified. Implicitly, the rest of the economy determines the process for $\Theta_{t}$ (and hence $w_{t}$, $r_{t}$, and $d_{t}$ ), but the assumptions above and much of the analysis below can abstract from those

\footnotetext{
12 Interiority is a standard assumption to ensure the household's policy functions are differentiable (e.g., Santos, 1991).
} 
details and simply treat $\Theta_{t}$ as an exogenous process from the point of view of the given household. However, in order to go from abstract, general expressions for risk aversion to more concrete, closed-form expressions, I follow Swanson $(2012,2018)$ and adopt three standard assumptions from the macroeconomics literature:

Assumption 5. The household is infinitesimal.

Assumption 6. The household is representative.

Assumption 7. The model has a nonstochastic steady state, at which $x_{t}=x_{t+k}$ for all $k=1,2$, $\ldots$, and $x \in\{c, u, l, a, w, r, d, \Theta\}$.

Assumption 5 implies that the given household's choices for $c_{t}$ and $u_{t}$ have no effect on the aggregate quantities $w_{t}, r_{t}, d_{t}$, and $\Theta_{t}$, determined in general equilibrium. (This is consistent with the earlier definition of $\Theta_{t}$ as an exogenous process to the household.) Assumption 6 states that aggregate consumption demand and labor supply are determined by a household sector that effectively has the same preferences as the given household (either explicitly or through Gorman aggregation). Assumption 7 is a restriction on how the general equilibrium of the economy behaves when there are no aggregate shocks and no aggregate uncertainty. Note that, throughout the paper, a variable without a time subscript will denote its steady-state value. ${ }^{13}$ Assumptions 6 and 7 together imply that, when the economy is at the nonstochastic steady state, the household finds it optimal to choose the steady-state values $c$ and $u$, given $a, l$, and $\Theta$.

It's important to note that Assumptions 6-7 do not prohibit us from offering an individual household a hypothetical idiosyncratic wealth gamble, as described below. The nonstochastic steady state of the model is only a reference point around which the aggregate variables $w, r, d$, and $\Theta$ and the other households' choices of $c, u, a$ and $l$ can be predicted with certainty. This reference point is important because it's only there that closed-form expressions for risk aversion can be computed in general.

Finally, many dynamic models have a balanced growth path rather than a steady state, as in King, Plosser, and Rebelo (1988). The results below carry over essentially unchanged to this case as well. For ease of exposition, Sections 3-5 assume the existence of a nonstochastic steady state, while the Appendix provides the corresponding results for the more general:

\footnotetext{
13 As in Swanson $(2012,2018)$, let the exogenous state $\Theta_{t}$ contain the variances of any shocks to the model, so that $(a, l ; \Theta)$ denotes the nonstochastic steady state, with the variances of any shocks (other than the hypothetical gamble described in the next section) set equal to zero; $c(a, l ; \Theta)$ corresponds to the household's optimal consumption choice at the nonstochastic steady state, etc.
} 
Assumption $7^{\prime}$. The model has a balanced growth path that can be renormalized to a nonstochastic steady state after a suitable change of variables.

\section{Risk Aversion}

\subsection{The Coefficient of Absolute Risk Aversion}

As in Swanson $(2012,2018)$, the household's attitudes toward risk at time $t$ depend on the state vector, $\left(a_{t}, l_{t} ; \Theta_{t}\right)$. Given this state, I consider the household's aversion to a hypothetical, idiosyncratic, one-shot gamble over wealth:

$$
a_{t+1}=\left(1+r_{t}\right) a_{t}+w_{t} l_{t}+d_{t}-c_{t}+\sigma \varepsilon_{t+1}
$$

where the gamble $\varepsilon_{t+1}$ is a random shock with bounded support $[\underline{\varepsilon}, \bar{\varepsilon}]$, mean zero, unit variance, independent of $\Theta_{\tau}$ for all times $\tau$, and independent of $a_{\tau}, l_{\tau}, c_{\tau}$, and $u_{\tau}$ for all $\tau \leq t$. Note that the gamble is dated $t+1$ to clarify that its outcome is not in the household's information set at time $t$, and note also that (7) is equivalent to a one-shot gamble over asset returns $r_{t}$. Indeed, thinking of the gamble as being over $r_{t}$ highlights the close connection between (7) and the household's willingness to hold a risky asset, which I will discuss further in Section 3.3, below.

Following Arrow (1964), Pratt (1965), and Swanson (2012, 2018), I ask what one-time fee $\mu$ the household would be willing to pay to avoid the gamble in (7):

$$
a_{t+1}=\left(1+r_{t}\right) a_{t}+w_{t} l_{t}+d_{t}-c_{t}-\mu \text {. }
$$

The quantity $\mu$ that makes the household indifferent between (7) and (8) is the household's "willingness to pay" to avoid the gamble.

Definition 1. Let $\left(a_{t}, l_{t} ; \Theta_{t}\right)$ be an interior point of $X$. Let $\widetilde{\mathbb{V}}\left(a_{t}, l_{t} ; \Theta_{t} ; \sigma\right)$ denote the value function for the household's optimization problem inclusive of the one-shot gamble (7), and let $\mu\left(a_{t}, l_{t} ; \Theta_{t} ; \sigma\right)$ denote the value of $\mu$ that satisfies $\mathbb{V}\left(a_{t}-\frac{\mu}{1+r_{t}}, l_{t} ; \Theta_{t}\right)=\widetilde{\mathbb{V}}\left(a_{t}, l_{t} ; \Theta_{t} ; \sigma\right)$. The household's coefficient of absolute risk aversion at $\left(a_{t}, l_{t} ; \Theta_{t}\right)$, denoted $R^{a}\left(a_{t}, l_{t} ; \Theta_{t}\right)$, is given by $R^{a}\left(a_{t}, l_{t} ; \Theta_{t}\right)=\lim _{\sigma \rightarrow 0} \mu\left(a_{t}, l_{t} ; \Theta_{t} ; \sigma\right) /\left(\sigma^{2} / 2\right)$.

Note that, in Definition 1, the household's willingness to pay $\mu$ depends on the state vector $\left(a_{t}, l_{t} ; \Theta_{t}\right)$ as well as the size of the gamble $\sigma$. As in Arrow (1964), Pratt (1965), and Swanson (2012, 2018), $R^{a}$ denotes the limit of the household's willingness to pay per unit of variance as 
this variance becomes small. Note that $R^{a}$ depends on the state vector $\left(a_{t}, l_{t} ; \Theta_{t}\right)$ because $\mu$ depends on that state.

Proposition 1 shows that $\widetilde{\mathbb{V}}\left(a_{t}, l_{t} ; \Theta_{t} ; \sigma\right), \mu\left(a_{t}, l_{t} ; \Theta_{t} ; \sigma\right)$, and $R^{a}\left(a_{t}, l_{t} ; \Theta_{t}\right)$ in Definition 1 are all well-defined and that $R^{a}\left(a_{t}, l_{t} ; \Theta_{t}\right)$ equals the "folk wisdom" value of $-\mathbb{V}_{11} / \mathbb{V}_{1}:{ }^{14}$

Proposition 1. Let $\left(a_{t}, l_{t} ; \Theta_{t}\right)$ be an interior point of $X$. Given Assumptions $1-5, \widetilde{\mathbb{V}}\left(a_{t}, l_{t} ; \Theta_{t} ; \sigma\right)$, $\mu\left(a_{t}, l_{t} ; \Theta_{t} ; \sigma\right)$, and $R^{a}\left(a_{t}, l_{t} ; \Theta_{t}\right)$ exist and

$$
R^{a}\left(a_{t}, l_{t} ; \Theta_{t}\right)=\frac{-E_{t} \mathbb{V}_{11}\left(a_{t+1}^{*}, l_{t+1}^{*} ; \Theta_{t+1}\right)}{E_{t} \mathbb{V}_{1}\left(a_{t+1}^{*}, l_{t+1}^{*} ; \Theta_{t+1}\right)},
$$

where $\mathbb{V}_{1}$ and $\mathbb{V}_{11}$ denote the first and second partial derivatives of $\mathbb{V}$ with respect to its first argument. Given Assumptions 6-7, (9) can be evaluated at the steady state to yield

$$
R^{a}(a, l ; \Theta)=\frac{-\mathbb{V}_{11}(a, l ; \Theta)}{\mathbb{V}_{1}(a, l ; \Theta)}
$$

Proof: See Appendix.

Equation (9) is valid very generally, without any representative agent or steady state assumptions, but can typically only be solved numerically. Equation (10), which imposes those additional assumptions, can be solved in closed form, as shown below.

As in Swanson (2012, 2018), Definition 1 and Proposition 1 imply that the household's coefficient of absolute risk aversion is determined by the curvature of the value function $\mathbb{V}$ with respect to wealth rather than the curvature of $U$ with respect to consumption. Because the value function depends on the economic state $\Theta_{t}$, risk aversion also depends on $\Theta_{t}$. This statedependence is standard in the literature on risk aversion as measured by willingness to pay to avoid a monetary or wealth gamble: for example, Stiglitz (1969), Constantinides (1990), and Campbell and Cochrane (1999) all note this state-dependence as well. ${ }^{15}$ Similarly, Epstein, Farhi,

\footnotetext{
${ }^{14}$ See Swanson (2012), Constantinides (1990), Farmer (1990), Campbell and Cochrane (1999), and Flavin and Nakagawa (2008). For the more general case of Epstein-Zin (1990) preferences, equation (9) no longer holds and there is no folk wisdom; see Swanson (2018) for the more general expressions corresponding to that case.

${ }^{15}$ Stiglitz (1969) shows that absolute and relative risk aversion in his static, multiple-good model are given by $-U_{y y} / U_{y}$ and $-y U_{y y} / U_{y}$, where the indirect utility function $U$ "is a function of both [income] $y$ and [prices] $p$ : $U=U(y, p)$. Arrow and Pratt assumed in effect that $p$ is constant" (Stiglitz, 1969, footnote 11). Thus, in Stiglitz (1969), risk aversion depends on the economic state - the price vector $p$. Constantinides (1990) states that "I define the RRA coefficient in terms of an atemporal gamble that changes the current level of capital by the outcome of the gamble... RRA $=-W V_{w w} / V_{w} \ldots$ The RRA coefficient is a function of wealth and of the state variables $x(t)$," (Constantinides, 1990, p. 527). Campbell and Cochrane (1999) note: "Risk aversion measures attitudes toward pure wealth bets and is therefore conventionally captured by the second partial derivative of the value function with respect to individual wealth..." (Campbell and Cochrane, 1999, p. 243), and risk aversion "depends on individual wealth $W$ and on aggregate variables that describe asset prices or investment opportunities..." (Campbell and Cochrane, 1999, p. 244). Note that this state-dependence is not a feature of the Kihlstrom-Mirman (1974, 1981) multi-dimensional definition of risk aversion mentioned in the Introduction; that approach is independent of the economic state and depends only on the household's preferences and total consumption bundle.
} 
and Strzalecki (2014) analyze a household's willingness to pay to resolve uncertainty earlier rather than later and show that this "timing premium" depends on the household's value function rather than period utility and thus also depends on the economic state (Epstein et al., 2014, p. 2686).

A practical difficulty with Proposition 1 is that the value function $\mathbb{V}$ cannot be solved in closed form even for very simple models with labor. However, closed-form solutions for $\mathbb{V}_{1}$ and $\mathbb{V}_{11}$ evaluated at the nonstochastic steady state can be computed even when the function $\mathbb{V}$ is unknown. For example, the Benveniste-Scheinkman equation,

$$
\mathbb{V}_{1}\left(a_{t}, l_{t} ; \Theta_{t}\right)=\left(1+r_{t}\right) U^{\prime}\left(c_{t}^{*}\right)
$$

implies that the marginal value of wealth equals the marginal utility of consumption times $1+r_{t}$ (the interest rate appears here because beginning-of-period assets generate income in period $t$ ). In (11), $U^{\prime}$ is a known function. Although the function $c^{*}\left(a_{t}, l_{t} ; \Theta_{t}\right)$ is not known in general, the point $c_{t}^{*}$ is known if we evaluate it at the nonstochastic steady state, $c$. Thus, we can compute $\mathbb{V}_{1}$ at the nonstochastic steady state by evaluating the right-hand side of (11) at that point. ${ }^{16}$

The second derivative $\mathbb{V}_{11}$ can be computed by noting that equation (11) holds for general $a_{t}$; hence we can differentiate it to yield

$$
\mathbb{V}_{11}\left(a_{t}, l_{t} ; \Theta_{t}\right)=\left(1+r_{t}\right) U^{\prime \prime}\left(c_{t}^{*}\right) \frac{\partial c_{t}^{*}}{\partial a_{t}}
$$

All that remains is to find the derivative $\partial c_{t}^{*} / \partial a_{t}$.

Intuitively, $\partial c_{t}^{*} / \partial a_{t}$ is just the household's marginal propensity to consume today out of a change in assets, which can be deduced from its Euler equation and budget constraint. Differentiating

$$
U^{\prime}\left(c_{t}^{*}\right)=\beta E_{t}\left(1+r_{t+1}\right) U^{\prime}\left(c_{t+1}^{*}\right)
$$

with respect to $a_{t}$ yields ${ }^{17}$

$$
U^{\prime \prime}\left(c_{t}^{*}\right) \frac{\partial c_{t}^{*}}{\partial a_{t}}=\beta E_{t}\left(1+r_{t+1}\right) U^{\prime \prime}\left(c_{t+1}^{*}\right) \frac{\partial c_{t+1}^{*}}{\partial a_{t}}
$$

\footnotetext{
${ }^{16}$ In Swanson (2012, 2018), I compare the closed-form expressions for risk aversion at the nonstochastic steady state to numerical solutions to equation (9) over a wide range of values for the state variables in a simple model, and show that the closed-form expressions are very good approximations. The same is true in the present paper, although those results are not reported in the interest of space. See the online appendix for details.

$$
17 \text { The notation } \frac{\partial c_{t+1}^{*}}{\partial a_{t}} \text { is taken to mean } \frac{\partial c_{t+1}^{*}}{\partial a_{t+1}} \frac{d a_{t+1}^{*}}{d a_{t}}+\frac{\partial c_{t+1}^{*}}{\partial l_{t+1}} \frac{d l_{t+1}^{*}}{d a_{t}}=\frac{\partial c_{t+1}^{*}}{\partial a_{t+1}}\left[\left(1+r_{t}\right)-\frac{\partial c_{t}^{*}}{\partial a_{t}}\right]+\frac{\partial c_{t+1}^{*}}{\partial l_{t+1}} f\left(\Theta_{t}\right) \frac{\partial u_{t}}{\partial a_{t}},
$$$$
\text { and analogously for } \frac{\partial c_{t+2}^{*}}{\partial a_{t}}, \frac{\partial c_{t+3}^{*}}{\partial a_{t}} \text {, etc. }
$$ 
Evaluating (14) at steady state, $\beta=(1+r)^{-1}$ and the $U^{\prime \prime}(c)$ terms cancel, giving

$$
\frac{\partial c_{t}^{*}}{\partial a_{t}}=E_{t} \frac{\partial c_{t+1}^{*}}{\partial a_{t}}=E_{t} \frac{\partial c_{t+k}^{*}}{\partial a_{t}}, \quad k=1,2, \ldots
$$

In other words, starting from steady state, whatever the change in the household's optimal consumption today, it must be the same as the change in the household's expected optimal consumption tomorrow and at each future date $t+k .^{18}$

The household's budget constraint is implied by asset accumulation equation (3) and the no-Ponzi condition (4). Differentiating (3) with respect to $a_{t}$, evaluating at steady state, and applying (4) gives

$$
\sum_{k=0}^{\infty} \frac{1}{(1+r)^{k}} E_{t}\left[\frac{\partial c_{t+k}^{*}}{\partial a_{t}}-w \frac{\partial l_{t+k}^{*}}{\partial a_{t}}\right]=1+r .
$$

In other words, the present discounted value of the change in consumption equals the change in assets plus the present discounted value of the change in labor income.

To solve for $\partial c_{t}^{*} / \partial a_{t}$ using equations (15)-(16), it only remains to solve for $\partial l_{t+k}^{*} / \partial a_{t}$. I do this in two steps, using the household's Euler equation for unemployment and the transition equation (2) for labor. The details of this computation are tangential to the main points of this section, so I summarize the result in the following lemma:

Lemma 1. Given Assumptions 1-7 and either $s<1$ or $f(\Theta)<1$, the household's expected marginal propensity to work at each future date $t+k, k=1,2, \ldots$, with respect to changes in assets at time $t$, evaluated at steady state, satisfies

$$
E_{t} \frac{\partial l_{t+k}^{*}}{\partial a_{t}}=-\frac{\gamma}{\chi} \frac{l+u}{c} \frac{f(\Theta)}{s+f(\Theta)}\left[1-(1-s-f(\Theta))^{k}\right] \frac{\partial c_{t}^{*}}{\partial a_{t}},
$$

where $\gamma \equiv-c U^{\prime \prime}(c) / U^{\prime}(c)$ is the elasticity of $U^{\prime}$ with respect to $c$, evaluated at steady state, and $\chi \equiv(l+u) V^{\prime \prime}(l+u) / V^{\prime}(l+u)$ the elasticity of $V^{\prime}$ with respect to $l+u$, evaluated at steady state.

Proof: See Appendix.

Note that, in response to a change in assets, household consumption jumps instantly to a new steady-state level, but $l$ responds only gradually, approaching a new steady-state asymptotically as $k \rightarrow \infty$. The household adjusts along the labor margin by relatively more when $\chi$ is low (i.e., the marginal disutility of working is flat), $\gamma$ is high (the marginal utility of consumption is curved), or the probability of finding a job $f(\Theta)$ is high.

\footnotetext{
${ }^{18}$ Note that equation (15) does not follow from the steady state assumption: for example, in a model with internal habits, considered in Swanson (2009), the household's optimal consumption response to a change in assets increases over time, even starting from steady state.
} 
Substituting (17) into the budget constraint (16) and solving for $\partial c_{t}^{*} / \partial a_{t}$ yields

$$
\frac{\partial c_{t}^{*}}{\partial a_{t}}=\frac{r}{1+w \frac{\gamma}{\chi} \frac{l+u}{c} \frac{f(\Theta)}{r+s+f(\Theta)}} .
$$

In response to an increase in assets, the household raises consumption in each period by the extra asset income, $r$ (as in the permanent income hypothesis), adjusted downward by $1+$ $w \frac{\gamma}{\chi} \frac{l+u}{c} \frac{f(\Theta)}{r+s+f(\Theta)}$, which takes into account the household's optimal decision to reduce hours worked and labor income. When $f(\Theta)$ is large relative to $r+s,(18)$ converges to the expression derived in Swanson (2012) for a frictionless labor market. Alternatively, when $f(\Theta)=0$, labor is exogenously fixed and (18) equals $r$, the traditional permanent income hypothesis value.

We can now express the household's coefficient of absolute risk aversion, evaluated at the steady state, in closed form. Substituting (11), (12), and (18) into (10) proves:

Proposition 2. Given Assumptions 1-7, the household's coefficient of absolute risk aversion, $R^{a}\left(a_{t}, l_{t} ; \Theta_{t}\right)$, evaluated at steady state, satisfies

$$
R^{a}(a, l ; \Theta)=\frac{-U^{\prime \prime}(c)}{U^{\prime}(c)} \frac{r}{1+w \frac{\gamma}{\chi} \frac{l+u}{c} \frac{f(\Theta)}{r+s+f(\Theta)}} .
$$

There are several features of Proposition 2 worth noting. If labor supply is exogenously fixed, corresponding to $s=f(\Theta)=0$, then risk aversion in (19) reduces to $-r U^{\prime \prime} / U^{\prime}$, the standard Arrow-Pratt definition multiplied by a scale factor $r$, which translates assets into current-period consumption units. ${ }^{19}$ More generally, when $f(\Theta)>0$, the household can partially offset shocks to assets by changing its hours of work. Even though consumption and labor are additively separable in (1), the household's consumption process is still connected to the labor market through the household's budget constraint. As a result, the household's aversion to a gamble over assets is related to its ability to offset asset fluctuations by varying hours of work.

A flexible labor margin implies that risk aversion is less than in the fixed-labor case:

Corollary 1. The coefficient of absolute risk aversion, $R^{a}\left(a_{t}, l_{t} ; \Theta_{t}\right)$, satisfies

$$
R^{a}(a, l ; \Theta) \leq \frac{-r U^{\prime \prime}(c)}{U^{\prime}(c)}
$$

If $r<1$, then (19) is also less than $-U^{\prime \prime} / U^{\prime}$.

\footnotetext{
${ }^{19}$ A gamble over a lump sum of $\$ x$ is equivalent to a gamble over an annuity of $\$ r x$. Thus, even though $\mathbb{V}_{11} / \mathbb{V}_{1}$ is different from $U^{\prime \prime} / U^{\prime}$ by a factor of $r$, this difference is exactly the same as a change from lump-sum units to annuity units.
} 
Note that, since $r$ is the net interest rate, $r \ll 1$ in typical calibrations.

I discuss the relationship between labor market flexibility, risk aversion, and risk premia below, after first defining relative risk aversion.

\subsection{The Coefficient of Relative Risk Aversion}

As in Arrow (1964), Pratt (1965), and Swanson (2012, 2018), relative risk aversion is defined by confronting the household with a one-shot gamble of size $A_{t}$ in period $t$,

$$
a_{t+1}=\left(1+r_{t}\right) a_{t}+w_{t} l_{t}+d_{t}-c_{t}+A_{t} \sigma \varepsilon_{t+1}
$$

and comparing it to a one-time fee $A_{t} \mu$, where $A_{t}$ is the household's wealth at time $t$. The gamble in (21) and willingness to pay $\mu$ are then relative to the household's wealth at time $t$. Proposition 1 easily generalizes to this case and implies that $\lim _{\sigma \rightarrow 0} 2 \mu(\sigma) / \sigma^{2}$ for this gamble is

$$
\frac{-A_{t} E_{t} \mathbb{V}_{11}\left(a_{t+1}^{*}, l_{t+1}^{*} ; \Theta_{t+1}\right)}{E_{t} \mathbb{V}_{1}\left(a_{t+1}^{*}, l_{t+1}^{*} ; \Theta_{t+1}\right)}
$$

Note that, in models with labor, the household's wealth $A_{t}$ can be difficult to define in some cases because the household's human capital can be hard to define (Swanson, 2012, 2018). ${ }^{20}$ These issues are tangential to the present paper, so for simplicity I define human capital here to be the present discounted value of labor earnings, as suggested by Swanson (2018). Equivalently, from the budget constraint (3)-(4), household wealth equals the present discounted value of consumption.

Definition 2. Let $\left(a_{t}, l_{t} ; \Theta_{t}\right)$ be an interior point of $X$. The household's coefficient of relative risk aversion, denoted $R^{c}\left(a_{t}, l_{t} ; \Theta_{t}\right)$, is given by $(22)$ with wealth $A_{t} \equiv\left(1+r_{t}\right)^{-1} E_{t} \sum_{\tau=t}^{\infty} m_{t, \tau} c_{\tau}^{*}$, the present discounted value of household consumption, where $m_{t, \tau}=\beta U^{\prime}\left(c_{\tau}\right) / U^{\prime}\left(c_{t}\right)$ denotes the household's stochastic discount factor.

The factor $\left(1+r_{t}\right)^{-1}$ in the definition expresses wealth $A_{t}$ in beginning- rather than end-of-period- $t$ units, so that in steady state $A=c / r$ and relative risk aversion is given by

$$
R^{c}(a, l ; \Theta)=\frac{-A \mathbb{V}_{11}(a, l ; \Theta)}{\mathbb{V}_{1}(a, l ; \Theta)}=\frac{\gamma}{1+w \frac{\gamma}{\chi} \frac{l+u}{c} \frac{f(\Theta)}{r+s+f(\Theta)}},
$$

\footnotetext{
${ }^{20}$ Note that the household's financial assets $a_{t}$ are not a good measure of wealth $A_{t}$, since $a_{t}$ for an individual household may be zero or negative at some points in time.
} 
where (23) makes use of the definition $\gamma=-c U^{\prime \prime}(c) / U^{\prime}(c)$. Note that if labor is exogenously fixed, so that $s=f(\Theta)=0$, equation (23) reduces to the usual Arrow-Pratt definition. But as long as the household has some ability to vary its hours of work, risk aversion is reduced by the factor in the denominator of $(23)$.

\subsection{Numerical Example}

The relationship between the labor margin, risk aversion, and risk premia can be seen in a simple real business cycle model with labor market frictions. ${ }^{21}$ Let the economy consist of a unit continuum of representative households, each with optimization problem (1)-(4) and period utility function

$$
U\left(c_{t}\right)-V\left(l_{t}+u_{t}\right) \equiv \frac{c_{t}^{1-\gamma}}{1-\gamma}-\chi_{0} \frac{\left(l_{t}+u_{t}\right)^{1+\chi}}{1+\chi}
$$

There is a unit continuum of perfectly competitive firms, each with production function

$$
y_{t}=Z_{t} k_{t}^{1-\phi} l_{t}^{\phi}
$$

where $y_{t}, l_{t}$, and $k_{t}$ denote firm output, labor, and beginning-of-period capital, respectively, and $Z_{t}$ denotes an exogenous aggregate productivity process that follows

$$
\log Z_{t}=\rho \log Z_{t-1}+\varepsilon_{t}
$$

where $\varepsilon_{t}$ is an i.i.d. shock with mean zero and variance $\sigma_{\varepsilon}^{2}$. Firms rent capital from households in a frictionless competitive market at rental rate $r_{t}^{k}$. Households accumulate capital according to

$$
k_{t+1}=\left(1+r_{t}\right) k_{t}+w_{t} l_{t}-c_{t}
$$

where $r_{t}=r_{t}^{k}-\delta$ and $\delta$ denotes the capital depreciation rate.

Firms hire labor by posting vacancies $v_{t}$ at a cost of $\kappa$ per vacancy per period. The number of workers employed by each firm evolves according to

$$
l_{t+1}=(1-s) l_{t}+h_{t},
$$

\footnotetext{
${ }^{21}$ Swanson $(2012,2018)$ compares risk aversion to the equity premium in several examples where households can vary their labor supply in a frictionless labor market.
} 
where $l_{t}$ is the number of workers employed by the firm and $h_{t}$ the number of new hires. ${ }^{22}$ New hires are determined by the Cobb-Douglas matching function, ${ }^{23}$

$$
h_{t}=\mu u_{t}^{1-\eta} v_{t}^{\eta}
$$

This implies the job-finding rate for households is

$$
f\left(\Theta_{t}\right)=\frac{h_{t}}{u_{t}}=\mu\left(\frac{v_{t}}{u_{t}}\right)^{\eta} .
$$

As is typical in these models, the job-finding rate depends only on the vacancy-unemployment ratio, $v_{t} / u_{t}$, which is often denoted by $\theta_{t}$. In the present paper, the aggregate state vector $\Theta_{t}$ is more general than this, but $f\left(\Theta_{t}\right)$ nevertheless depends only on $v_{t} / u_{t}$ in this example.

At the beginning of each period $t$, workers and firms who were matched in the previous period bargain over the wage $w_{t}$. If negotiations break down, the worker and firm each can search for a new match in period $t$. Let $J_{t}$ denote the representative firm's surplus from hiring an additional worker in period $t$ :

$$
J_{t}=\phi \frac{y_{t}}{l_{t}}-w_{t}+(1-s) E_{t} m_{t+1} J_{t+1}
$$

The firm's surplus is the difference between the marginal product of labor and the wage this period, plus the expected discounted value of the firm surplus next period, if the match persists, where firms discount the future using the representative household's stochastic discount factor, $m_{t+1}=\beta c_{t+1}^{-\gamma} / c_{t}^{-\gamma}$.

Let $S_{t}$ denote the representative household's marginal surplus from employment,

$$
S_{t}=w_{t}+\left(1-s-f\left(\Theta_{t}\right)\right) E_{t} m_{t+1} S_{t+1}
$$

The household's surplus, relative to being unemployed, is the wage plus the expected discounted value of the surplus next period, if the match persists. (For simplicity, I assume that there is no compensation for being unemployed; also note that the household incurs marginal disutility

\footnotetext{
22 Note that both firms and households are representative and have unit measure, so the number of workers employed by each firm and the number of household members who work is given by $l_{t}$.

${ }^{23}$ Some authors interpret the Cobb-Douglas matching function in (29) to be $h_{t}=\max \left\{\mu u_{t}^{1-\eta} v_{t}^{\eta}, u_{t}\right\}$ so that $h_{t} \leq u_{t}$. However, $h_{t} \leq u_{t}$ holds around the steady state in this example, so including this max operator does not affect numerical solutions local to the model's steady state.
} 
Table 1: Benchmark Parameter Values

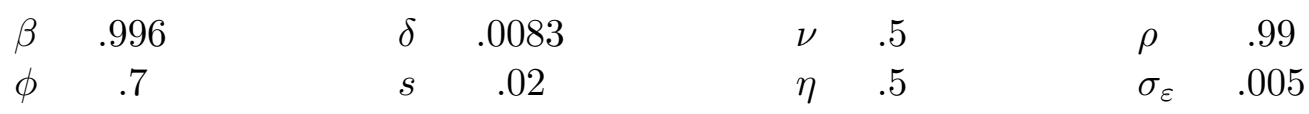

(a) Expected Utility Preferences

$\begin{array}{ll}\gamma & 100 \\ \chi & 100\end{array}$ (b) Epstein-Zin Preferences

$\begin{array}{lc}\gamma & 3 \\ \chi & 3 \\ \alpha & -130\end{array}$

Benchmark parameter values for numerical example with (a) expected utility and (b) Epstein-Zin preferences. Parameters are calibrated to monthly data; $\chi_{0}, \kappa$, and $\mu$ are set to achieve steady-state values of $l+u=0.3, v / u=0.6$, and $f(\Theta)=0.28$, respectively. Expected utility benchmark values for $\gamma$ and $\chi$ are high in order to achieve a sizeable equity premium, but a wide range for these parameter values is considered in Figure 1, below. See text for details.

$V^{\prime}\left(l_{t}+u_{t}\right)$ whether the individual works or is unemployed. $)^{24}$

The wage $w_{t}$ in each period is set by Nash bargaining, so that

$$
(1-\nu) S_{t}=\nu J_{t}
$$

where $\nu \in[0,1]$ denotes the household's Nash bargaining weight.

In equilibrium, the marginal cost and marginal benefit to the firm of hiring a worker are equal, so

$$
J_{t}=\kappa \frac{v_{t}}{h_{t}}=\frac{\kappa}{\mu}\left(\frac{v_{t}}{u_{t}}\right)^{1-\eta} .
$$

Similarly, the marginal cost and benefit to the household of searching for a job are equal, giving the household's unemployment Euler equation (equation (A14) in the Appendix).

As discussed in Shimer (2010), models with frictional labor markets are more naturally calibrated to monthly than to quarterly data, because unemployed workers in the U.S. typically find jobs in less than one quarter. Benchmark values for the model's parameters are reported in Table 1. I set the household's discount factor $\beta$ to .996, as in Shimer (2010), implying an annual real interest rate of about 5 percent. Labor's share of output, $\phi$, is set to 0.7 , and the capital depreciation rate $\delta$ to .0083 , about 10 percent per year. Following Shimer (2010), I set the exogenous job separation rate $s$ to .02 , the wage bargaining parameter $\nu$ to 0.5 , and the matching

\footnotetext{
${ }^{24}$ Let $\mathbb{V}_{t}^{E}, \mathbb{V}_{t}^{U}$, and $\mathbb{V}_{t}^{H}$ denote the value to the household of an individual being employed, unemployed, and at home, respectively. Then $\mathbb{V}_{t}^{E}=w_{t}-V^{\prime}\left(l_{t}+u_{t}\right) / U^{\prime}\left(c_{t}\right)+(1-s) E_{t} m_{t+1} \mathbb{V}_{t+1}^{E}+s E_{t} m_{t+1} \mathbb{V}_{t+1}^{U}$. Because there is no compensation for unemployment, $\mathbb{V}_{t}^{U}=-V^{\prime}\left(l_{t}+u_{t}\right) / U^{\prime}\left(c_{t}\right)+f\left(\Theta_{t}\right) E_{t} m_{t+1} \mathbb{V}_{t+1}^{E}+\left(1-f\left(\Theta_{t}\right)\right) E_{t} m_{t+1} \mathbb{V}_{t+1}^{U}$. Define $S_{t}=\mathbb{V}_{t}^{E}-\mathbb{V}_{t}^{U}$. Note that individuals can move freely between unemployment and home production, so $\mathbb{V}_{t}^{U}=\mathbb{V}_{t}^{H}$. Thus, $\mathbb{V}_{t}^{H}$ does not need to be computed to derive $S_{t}$, although $\mathbb{V}_{t}^{H}=H^{\prime}\left(h_{t}\right)+E_{t} m_{t+1} \mathbb{V}_{t}^{H}$, using the notation in the Appendix. It follows that $\mathbb{V}_{t}^{H}>0, \mathbb{V}_{t}^{U}>0$, and $\mathbb{V}_{t}^{E}>\mathbb{V}_{t}^{U}$.
} 
function elasticity $\eta$ to 0.5 . Firms' cost of posting a vacancy, $\kappa$, is calibrated to set $v / u=0.6$ in steady state, consistent with the estimates in den Haan, Ramey, and Watson (2000) and Hall (2005). I calibrate the matching function productivity parameter, $\mu$, to set $f(\Theta)=0.28$ in steady state, consistent with the estimate in Shimer (2012). The exogenous productivity process is calibrated to have a monthly persistence $\rho=0.99$, corresponding to a quarterly persistence of about 0.97, and a shock standard deviation of $\sigma_{\varepsilon}=.005$, as in Shimer (2010).

For the household's period utility function, I set the benchmark values for $\gamma$ and $\chi$ to 100 each. These are high values, which are necessary to generate a sizeable equity premium in the model, but I also consider much lower values for these parameters in Figure 1, below. In addition, I consider an extension of the model to the case of Epstein-Zin preferences, as in Rudebusch and Swanson (2012) and Swanson (2018), which allow for more standard values for $\gamma$ and $\chi$ while still having sufficiently high risk aversion to produce a significant equity premium. With Epstein-Zin preferences, the household maximizes the generalized discounted value $\mathbb{V}_{t}^{\mathrm{ez}}$, defined recursively as

$$
\mathbb{V}_{t}^{\mathrm{ez}}=\frac{c_{t}^{1-\gamma}}{1-\gamma}-\chi_{0} \frac{\left(l_{t}+u_{t}\right)^{1+\chi}}{1+\chi}+\beta\left(E_{t}\left(\mathbb{V}_{t+1}^{\mathrm{ez}}\right)^{1-\alpha}\right)^{1 /(1-\alpha)}
$$

The case $\alpha=0$ in (35) corresponds to standard expected utility preferences. When $\gamma>1$, the period utility function in (35) and $\mathbb{V}_{t}^{\mathrm{ez}}$ are always negative, so (35) should be interpreted as

$$
\mathbb{V}_{t}^{\mathrm{ez}}=\frac{c_{t}^{1-\gamma}}{1-\gamma}-\chi_{0} \frac{\left(l_{t}+u_{t}\right)^{1+\chi}}{1+\chi}-\beta\left(E_{t}\left(-\mathbb{V}_{t+1}^{\mathrm{ez}}\right)^{1-\alpha}\right)^{1 /(1-\alpha)}
$$

to avoid problems with complex numbers. In this case, the household is more risk averse the more negative is the value of $\alpha$. In general, the coefficient of relative risk aversion $R^{c}$ for these preferences, with labor market frictions, can be found by a straightforward combination of the results in Swanson (2018) and the present paper. ${ }^{25}$ For these preferences, I set $\gamma$ and $\chi$ each to 3, which is in line with typical parameterizations in the literature (e.g., Del Negro, Giannoni, and

\footnotetext{
${ }^{25}$ Applying the methods in Swanson (2018), it's straightforward to show that the coefficient of relative risk aversion $R^{c}$ for the Epstein-Zin specification (35)-(36) is given by

$$
R^{c}(a, l ; \Theta)=\frac{-c \mathbb{V}_{11}^{\mathrm{ez}}}{\mathbb{V}_{1}^{\mathrm{ez}}}+\alpha \frac{c \mathbb{V}_{1}^{\mathrm{ez}}}{\mathbb{V}^{\mathrm{ez}}},
$$

where $\mathbb{V}^{\text {ez }}$ is a function of $\left(a_{t}, l_{t} ; \Theta_{t}\right)$, and $\mathbb{V}_{1}^{\text {ez }}$ and $\mathbb{V}_{11}^{\text {ez }}$ denote the first and second partial derivatives of $\mathbb{V}^{\text {ez }}$ with respect to its first argument, evaluated at steady state, $(a, l ; \Theta)$. Applying the methods of this paper, above, gives

$$
R^{c}(a, l ; \Theta)=\frac{\gamma}{1+w \frac{\gamma}{\chi} \frac{l+u}{c} \frac{f(\Theta)}{r+s+f(\Theta)}}+\alpha \frac{1-\gamma}{1-\chi_{0} \frac{1-\gamma}{1+\chi} \frac{(l+u)^{1+\chi}}{c^{1-\gamma}}}
$$
}


Schorfheide, 2015). ${ }^{26}$ I then set $\alpha=-130$ to generate a sizeable equity premium in the model. ${ }^{27}$

For both the expected utility and Epstein-Zin specifications, I calibrate the period utility parameter $\chi_{0}$ to set $l+u=0.3$ in steady state; that is, the household is assumed to devote about 30 percent of its time endowment to market work and labor market search.

An equity security in the model is defined to be a levered claim on the aggregate consumption stream, where aggregate consumption $C_{t}=c_{t}$ in equilibrium. The ex-dividend price of the consumption claim, $p_{t}$, satisfies

$$
p_{t}=E_{t} m_{t+1}\left(C_{t+1}^{\lambda}+p_{t+1}\right) \text {, }
$$

where $\lambda$ is the degree of leverage, which I calibrate to $\lambda=4 .{ }^{28}$ The equity premium, $\psi_{t}$, is defined to be the expected excess return,

$$
\psi_{t} \equiv \frac{E_{t}\left(C_{t+1}^{\lambda}+p_{t+1}\right)}{p_{t}}-\left(1+r_{t}^{f}\right)
$$

where $\left(1+r_{t}^{f}\right) \equiv 1 /\left(E_{t} m_{t+1}\right)$ denotes the one-period gross risk-free interest rate.

For any given set of parameter values, I solve the model numerically using perturbation methods, as in Swanson $(2012,2018)$; in particular, I compute an $n$ th-order Taylor series approximation to the true nonlinear solution to the model around its nonstochastic steady state. (Results in the figures below are for a fifth-order approximation, $n=5$.) The numerical algorithm is described in more detail in Swanson (2012) and Swanson, Anderson, and Levin (2006). Aruoba, Fernández-Villaverde, and Rubio-Ramírez (2006) compare a variety of numerical methods applied to a standard RBC model and find that the fifth-order perturbation solution is one of the most accurate methods globally as well as the fastest to compute.

Figure 1 graphs the equity premium and relative risk aversion $R^{c}$ as functions of $\chi, \gamma$, and $f(\Theta)$, holding the values of the other model parameters fixed at their benchmark values in

\footnotetext{
${ }^{26}$ Del Negro, Giannoni, and Schorfheide (2015), following Smets and Wouters (2007), use a household preference specification with habits that is not additively separable in consumption and labor. However, their estimated parameter values imply an intertemporal elasticity of subsitution and a Frisch elasticity of labor supply that are each about $1 / 3$.

27 Thus, the model matches the equity premium by assuming that households have high risk aversion. An alternative approach is to make the model more risky, such as by adding model uncertainty (e.g., Barillas, Hansen, and Sargent, 2009), rare disasters (Barro, 2006), long-run risks (Bansal and Yaron, 2004), or heterogeneous agents with uninsurable idiosyncratic risks (Constantinides and Duffie, 1996; Schmidt, 2016). In the interest of simplicity, I don't consider those extensions to the model here. However, Barillas et al. (2009) show a formal equivalence between model uncertainty and Epstein-Zin preferences with a high degree of risk aversion, and Schmidt (2016) makes a similar observation for uninsurable idiosyncratic risk.

${ }^{28}$ Note that $\lambda$ stands in for two types of firm leverage in the data: explicit financial leverage (debt vs. equity), and operational leverage, which results from fixed costs of production, wage and input price contracts, etc. See, e.g., García-Feijóo and Jorgensen (2010) for details and estimates.
} 
(a) Expected Utility Preferences
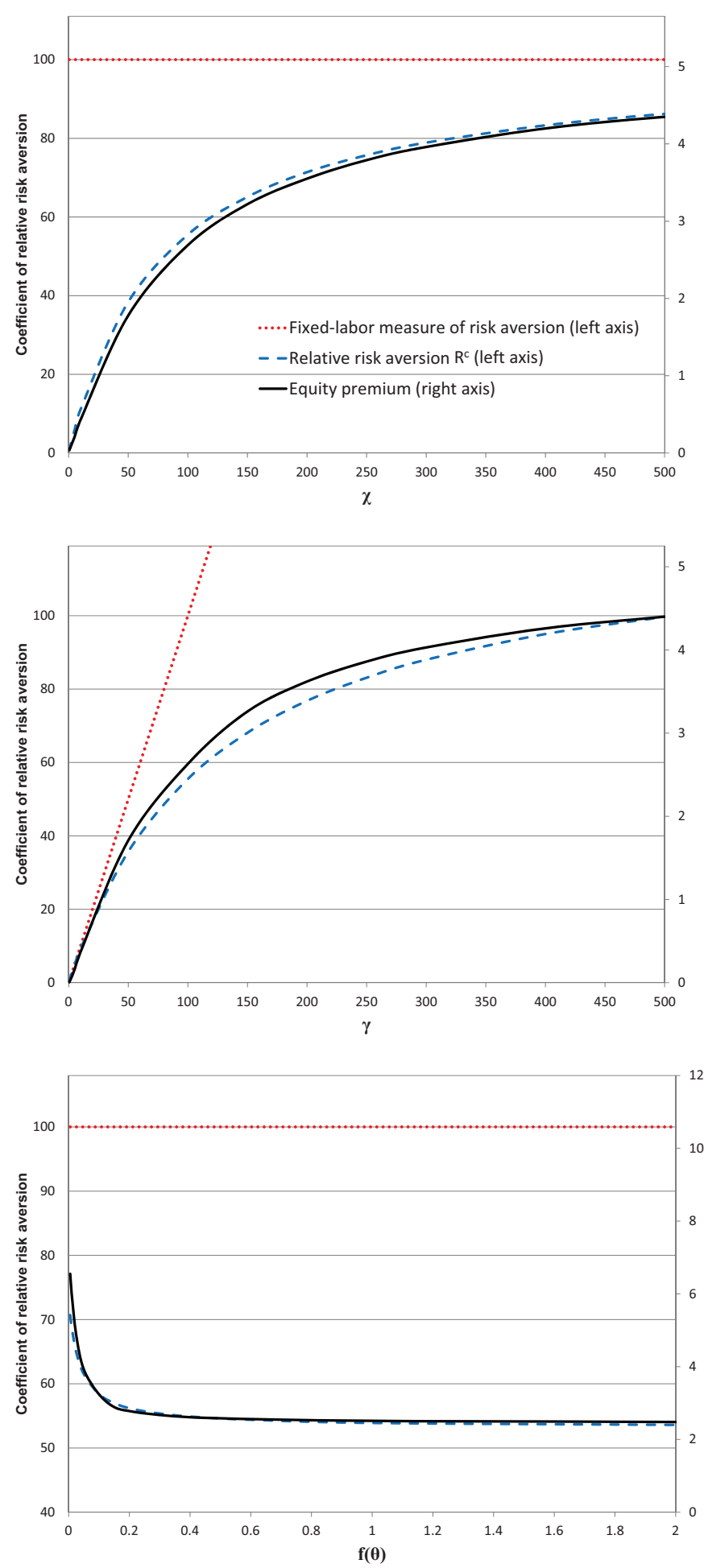

(b) Epstein-Zin Preferences
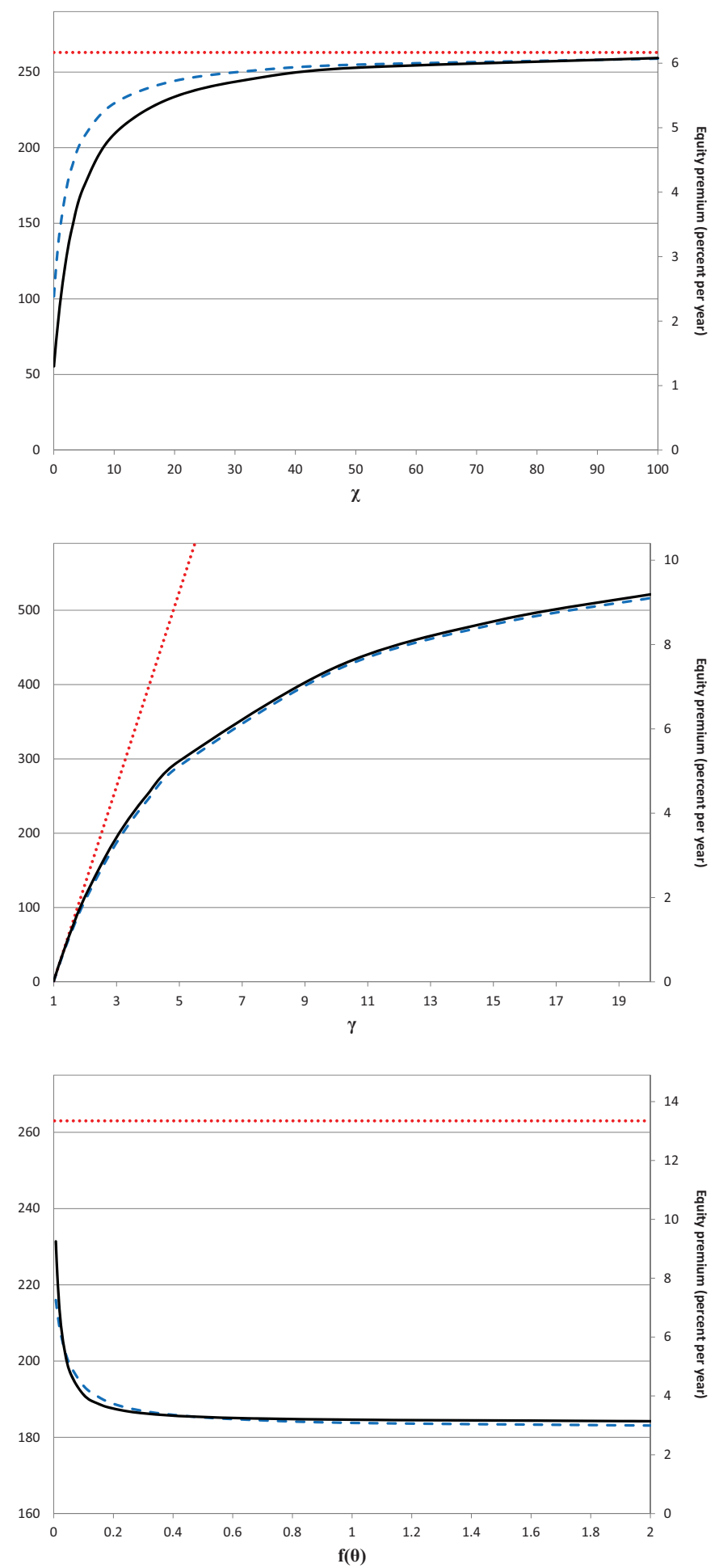

Figure 1. Coefficient of relative risk aversion $R^{c}$ and the equity premium in a real business cycle model with labor market frictions and (a) expected utility preferences, or (b) Epstein-Zin preferences. In each panel, one model parameter is varied while the others are fixed at their benchmark values, reported in Table 1. In each panel, the equity premium tracks relative risk aversion $R^{c}$ closely and is generally unrelated to the fixed-labor measure of risk aversion. See text and Table 1 for details. 
Table $1^{29}$ The first column reports results for the model with expected utility preferences, and the second column the model with Epstein-Zin preferences. In each panel, the dotted red line graphs the traditional, fixed-labor measure of risk aversion $(\gamma$ for expected utility, $\gamma+\alpha(1-\gamma)$ for Epstein-Zin), while the dashed blue line graphs relative risk aversion $R^{c}$ (given by equation $(23)$ for expected utility, or footnote 25 for Epstein-Zin). The solid black line in each panel plots the model-implied average equity premium against the right axis.

In Figure 1, the equity premium tracks relative risk aversion $R^{c}$ closely and is essentially unrelated to the traditional, fixed-labor measure of risk aversion. In the top-left panel, $\gamma$ is constant at 100 while relative risk aversion $R^{c}$ varies widely along with $\chi$, consistent with the wide variation in the equity premium. In the top-right panel, the story is essentially the same: $\gamma+\alpha(1-\gamma)$ is constant at 263 while realtive risk aversion $R^{c}$ varies widely, in line with the variation in the equity premium. In the two middle panels, the equity premium does not increase linearly with $\gamma$, but instead follows a concave trajectory that matches relative risk aversion $R^{c}$ closely. In the bottom panels, the fixed-labor measures of risk aversion are constant while $R^{c}$ and the equity premium increase sharply with labor market rigidity - that is, as the job-finding rate $f(\Theta)$ approaches zero. ${ }^{30}$

One might wonder why the specification with Epstein-Zin preferences, in the right-hand column of Figure 1, typically has higher values for risk aversion than the Expected Utility specification in the left-hand column. The reason is that the intertemporal elasticity of substitution is much lower in the left-hand column, so that consumption and the cash flows from the consumption claim are much more volatile in that column. If we instead set the dividend process in the two columns to be the same, then the equity premium is generally similar across the two columns for similar levels of risk aversion $R^{c}$.

There are a number of important points to take away from Figure 1. First, as in Swanson (2012, 2018), the traditional, fixed-labor measure of risk aversion has essentially no relationship to the price of risky assets when households can vary their labor supply; instead, the household's relative risk aversion $R^{c}$ is much more closely related to the equity premium. (Figure 1 shows this is true for the model with labor market frictions as well as the frictionless models considered

\footnotetext{
${ }^{29}$ Variation in $f(\Theta)$ is achieved by varying the matching function productivity parameter $\mu$.

${ }^{30}$ As $f(\Theta) \rightarrow 0$, relative risk aversion does not approach the fixed-labor measure $\gamma$ because the parameters $\chi_{0}$ and $\kappa$ are also changing to keep $l+u=0.3$ and $v / u=0.6$ in steady state (see Table 1 and its discussion). As a result, $l$ and $c$ in equation (23) both vanish as $f(\Theta) \rightarrow 0$, so the limit of equation (23) is not $\gamma$, and the limit of footnote 25 is not $\gamma+\alpha(1-\gamma)$.
} 
in Swanson $(2012,2018)$.) Moreover, the difference between relative risk aversion $R^{c}$ and the fixed-labor measure of risk aversion can be very large, as in the top panels of Figure 1, where relative risk aversion $R^{c}$ can be arbitrarily small as $\chi$ becomes small. Finally, the bottom panels of Figure 1 show how household risk aversion $R^{c}$ depends on the job finding rate $f\left(\Theta_{t}\right)$ : if $f\left(\Theta_{t}\right)$ is high, the household can easily vary its labor supply and better insure itself from shocks to asset values, while if $f\left(\Theta_{t}\right)$ is low, it's more difficult to do so and the household requires a higher premium to bear that risk. The shape of the curves in these bottom panels is also interesting: a relatively modest job-finding rate of $f(\Theta)=0.2$ provides the household with almost all of the benefits of perfect labor market flexibility (large $f\left(\Theta_{t}\right)$ ). This is because the household's discount rate in the model is not very high, and if it only takes a few months to vary labor supply, then that delay is not very costly, compared to being unable to adjust labor supply at all. Thus, the household can reap almost all of the benefits of flexible labor as long as it can adjust its labor within a few months. ${ }^{31}$

Finally, for robustness, I also consider two alternative definitions of the equity premium in the model. First, I define an equity security to be a claim on one unit of the firm's surplus from matching with a worker. Second, I define an equity security to be a claim on one unit of the capital stock (and add capital adjustment costs to the model to allow the price of captial to deviate from unity). ${ }^{32}$ In a simple RBC model like the one defined above, the dividends from these alternate equity securities are highly correlated with consumption $C_{t}$ : for the baseline parameterization considered in Table 1, with Epstein-Zin preferences, the correlation between $C_{t}$ and the firm's divident from the labor match, $\phi y_{t} / l_{t}-w_{t}$, is $85 \%$, while the correlation between $C_{t}$ and the net marginal product of capital, $r_{t}$, is also $85 \%$. As a result, the equity premium on these two alternate securities is very similar to the equity premium on the consumption claim: the equity premium on the (levered) labor match surplus is $3.33 \%$, the premium on the (levered) claim on a unit of capital is $3.80 \%$, and the premium on the consumption claim is $3.43 \%$. Because the consumption claim is the simplest of these three securities, and the most widely comparable in

\footnotetext{
${ }^{31}$ One can also decompose the equity premium in Figure 1 into a "quantity of risk" and a "price of risk" term, as in Cochrane (2005). That decomposition shows that the variation in the equity premium in Figure 1 is driven by variation in the price of risk rather than the quantity, and that the variation in the price of risk moves in line with the relative risk aversion coefficient $R^{c}$. See the online appendix for additional details.

${ }^{32}$ I assume that capital adjustment costs are quadratic and follow Jermann (1998) in calibrating the elasticity of investment/capital with respect to Tobin's $q$ to 0.25 . I keep the other parameters of the model the same as in Table 1(b), except for the Epstein-Zin parameter $\alpha$, which I reduce in magnitude from -130 to -55 . This is because, with capital adjustment costs, consumption $C_{t}$ is more volatile, so the model doesn't need as much risk aversion to match the equity premium.
} 
the literature, I've left the baseline results above in terms of the consumption claim.

\section{Implications of Labor Market Frictions for Risk Aversion}

Intuitively, labor market frictions make it more difficult for households to insure themselves from asset fluctuations by varying hours of work. Thus, a greater degree of labor market frictions should imply higher risk aversion, all else equal. That effect is evident in the bottom panel of Figure 1; in the present section, I analyze the implications of labor market frictions for risk aversion more generally.

The transition equation (2) for labor, evaluated at steady state, implies

$$
s l=f(\Theta) u
$$

Equation (39) can be used to substitute out $f(\Theta) u / l$ in $(23)$ to obtain

$$
R^{c}(a, l ; \Theta)=\frac{\gamma}{1+\frac{\gamma}{\chi} \frac{w l}{c} \frac{s+f(\Theta)}{r+s+f(\Theta)}}
$$

If labor is perfectly fixed, corresponding to the case $s=f(\Theta)=0$, equation (40) reduces to the usual Arrow-Pratt definition, $\gamma$. As the ratio $(s+f(\Theta)) /(r+s+f(\Theta))$ approaches 1 , equation (40) converges to the formula for risk aversion for the case where labor is perfectly flexible, reported in Swanson (2012). ${ }^{33}$ Thus, $(s+f(\Theta)) /(r+s+f(\Theta))$ lies between 0 and 1 and can be thought of as an index of labor market flexibility, with 0 corresponding to perfect rigidity and 1 to perfect flexibility. The interest rate $r$ appears in this index because labor frictions only delay the household's labor adjustment, rather than prevent it, and $r$ is related to the cost of this delay. Households that are very patient (have a low $r$ ) view labor market frictions as less costly, because they can adjust their labor supply as desired given enough time to do so. This labor market flexilibity index features prominently in the quantitative analysis of the next section.

Equation (39) can also be used to substitute out $f(\Theta)$ in (23), giving

$$
R^{c}(a, l ; \Theta)=\frac{\gamma}{1+\frac{\gamma}{\chi} \frac{w l}{c} \frac{s(1+(l / u))}{r+s(1+(l / u))}}
$$

\footnotetext{
33 Technically, $|1-s-f(\Theta)|<1$ is required to solve equation (A17) forward, so $s+f(\Theta) \in(0,2)$ and the ratio $(s+f(\Theta)) /(r+s+f(\Theta))$ has a maximum of $2 /(r+2)$. However, for small enough $r$ this ratio can be arbitrarily close to 1 .
} 
$R^{c}(a, l ; \Theta)$ is decreasing in $s(1+(l / u))$, holding fixed the other quantities in equation (41). This suggests that greater labor market frictions (lower $s$ ) or a recession (lower $l / u$ ) should correspond to higher levels of risk aversion. The remainder of this section makes these two points more rigorously and investigates their quantitative importance.

The following assumption is not strictly necessary, but helps to simplify the discussion and intuition in the analysis below:

Assumption 8. The elasticity $-c_{t} U^{\prime \prime}\left(c_{t}\right) / U^{\prime}\left(c_{t}\right)=\gamma$ for all $c_{t} \in \Omega_{c}$, the elasticity $\left(l_{t}+u_{t}\right) V^{\prime \prime}\left(l_{t}+\right.$ $\left.u_{t}\right) / V^{\prime}\left(l_{t}+u_{t}\right)=\chi$ for all $l_{t}+u_{t} \in \Omega_{l u}$, and $w l=c$.

Assumption 8 implies that $U$ and $V$ each have an isoelastic functional form, as in the numerical example above. The assumption $w l=c$ is equivalent to $r a+d=0$, from the household's flow budget constraint (3); this will be the case, for example, if there are no assets in steady state and no transfers in the model, or alternatively if lump-sum taxes offset the household's asset income. The crucial feature of Assumption 8 is that $\gamma, \chi$, and $w l / c$ in (40)-(41) can be regarded as stable compared to $s(1+(l / u))$. The intuition and basic results in the analysis below continue to hold if Assumption 8 holds only approximately rather than exactly. However, if any of $\gamma, \chi$, or $w l / c$ vary substantially, then the analytical results below may not hold and one would have to resort to numerical solutions of a given model to determine the variation in (40)-(41). ${ }^{34}$

\subsection{Risk Aversion Is Higher in More Frictional Labor Markets}

Labor markets are more frictional when $f(\Theta)$ is lower - when it is harder for an unemployed worker to find a job. The following proposition characterizes the relationship between $f(\Theta)$ and risk aversion:

Proposition 3. Let $f_{1}, f_{2}: \Omega_{\Theta} \rightarrow[0,1]$, and let the other parameters of the household's optimization problem be held fixed. Given Assumptions $1-8$, let $\left(a_{1}, l_{1} ; \Theta_{1}\right)$ and $\left(a_{2}, l_{2} ; \Theta_{2}\right)$ denote the steady-state values of $\left(a_{t}, l_{t} ; \Theta_{t}\right)$ corresponding to $f_{1}$ and $f_{2}$, respectively, and let $R_{1}^{c}\left(a_{1}, l_{1} ; \Theta_{1}\right)$ and $R_{2}^{c}\left(a_{2}, l_{2} ; \Theta_{2}\right)$ denote the corresponding values of risk aversion from (40). If $f_{1}\left(\Theta_{1}\right)<f_{2}\left(\Theta_{2}\right)$, then $R_{1}^{c}\left(a_{1}, l_{1} ; \Theta_{1}\right)>R_{2}^{c}\left(a_{2}, l_{2} ; \Theta_{2}\right)$.

\footnotetext{
${ }^{34}$ For example, suppose that $r a+d>0$ (i.e., $c>w l$ ). For the numerical example considered earlier, a higher degree of labor market frictions (lower $f(\Theta)$ ) causes $l$ to be lower and $u$ to be higher in steady state. Lower $l$ causes the MPK to be lower, ceteris paribus, and thus $k$ must be lower to bring the return $r^{k}$ back in line with the household's discount factor. Thus, steady-state $y$ and $c$ are lower. On net, it turns out that the ratio $w l / c$ is lower. Thus, as $f(\Theta)$ decreases, the ratio $w l / c$ also falls. This reinforces the effect in equation (40). Thus, the conclusions of Proposition 3, below, are strengthened if we recognize that the ratio $w l / c$ can vary in the numerical example considered earlier.
} 
Proof: Since $1+r=1 / \beta, r$ is independent of $f(\Theta)$. Assumption 8 then implies $R^{c}(a, l ; \Theta)$ in equation (40) is decreasing in $f(\Theta)$.

Consistent with the intuition presented earlier, Proposition 3 shows that a more rigid labor market implies greater risk aversion. The case $f(\Theta)=s=0$ corresponds to complete labor market rigidity and leads to the maximal level of household risk aversion, $\gamma$.

Proposition 3 is interesting because it suggests that economies with more frictional labor markets should also have higher risk premia. For example, if labor markets in Europe are characterized by lower job-finding probabilities $f(\Theta)$ than in the U.S., then Propostion 3 implies risk aversion in those countries should be higher than in the U.S. I investigate the quantitative importance of this effect below.

Proposition 3 is also interesting because it holds regardless of how the production side of the economy is specified, so long as Assumptions 1-8 for the household's problem are satisfied. The details of the production function and matching technology will generally affect the stochastic process for $\Theta_{t}$ and the functional form of $f$, but do not affect the conclusions of the proposition.

Finally, it may be tempting to conclude from (40) that $R^{c}$ is decreasing in $s$ as well as $f(\Theta)$, but that is not necessarily the case. Changes in $s$ may affect the steady-state level of $\Theta$ and thus $f(\Theta)$ - for example, a lower value of $s$ tends to increase $l / u$, which increases $f(\Theta)$ in standard labor market search models. Thus, the effect of $s$ on $R^{c}$ in (40) is ambiguous. The following corollary correctly characterizes the relationship between $s$ and risk aversion:

Corollary 2. Let $s_{1}, s_{2} \in[0,1], f_{1}, f_{2}: \Omega_{\Theta} \rightarrow[0,1]$, and let the other parameters of the household's optimization problem be held fixed. Given Assumptions $1-8$, let $\left(a_{1}, l_{1} ; \Theta_{1}\right)$ and $\left(a_{2}, l_{2} ; \Theta_{2}\right)$ denote the steady-state values of $\left(a_{t}, l_{t} ; \Theta_{t}\right)$ corresponding to $\left(s_{1}, f_{1}\right)$ and $\left(s_{2}, f_{2}\right)$, respectively, and $R_{1}^{c}\left(a_{1}, l_{1} ; \Theta_{1}\right)$ and $R_{2}^{c}\left(a_{2}, l_{2} ; \Theta_{2}\right)$ the corresponding values of risk aversion (40). If $s_{1}<s_{2}$ and $f_{1}\left(\Theta_{1}\right) \leq f_{2}\left(\Theta_{2}\right)$, then $R_{1}^{c}\left(a_{1}, l_{1} ; \Theta_{1}\right)>R_{2}^{c}\left(a_{2}, l_{2} ; \Theta_{2}\right)$. More generally, if $s_{1}+f_{1}\left(\Theta_{1}\right)<$ $s_{2}+f_{2}\left(\Theta_{2}\right)$, then $R_{1}^{c}\left(a_{1}, l_{1} ; \Theta_{1}\right)>R_{2}^{c}\left(a_{2}, l_{2} ; \Theta_{2}\right)$.

Proof: Since $1+r=1 / \beta, r$ is independent of $s$ and $f$. Assumption 8 then implies $R^{c}(a, l ; \Theta)$ in equation (40) is increasing in $s+f(\Theta)$.

\subsection{Risk Aversion Is Higher in Recessions}

Intuitively, a recession is a period in which employment is low and unemployment is high, or $l / u$ is low. The following proposition characterizes the relationship between $l / u$ and risk aversion: 
Proposition 4. Given Assumptions 1-8 and fixed values for the parameters s, $\beta$, $\gamma$, and $\chi$, $R^{c}(a, l ; \Theta)$ is decreasing in $l / u$.

Proof: Since $1+r=1 / \beta, r$ is independent of $l / u$. Assumption 8 then implies $R^{c}(a, l ; \Theta)$ in equation (41) is decreasing in $l / u$.

Proposition 4 shows that risk aversion is higher in recessions. A lower ratio of employment to unemployment implies that it is harder for unemployed workers to find a job, because $f(\Theta)=s l / u$. As a result, it is more difficult for households to use the labor market to insure themselves from asset fluctuations.

Note that the source of the change in $l / u$ in Proposition 4 is irrelevant. The ratio $l / u$ could be lower because of a decrease in the efficiency of the matching function, a fall in firm productivity, a fall in government purchases, or a change in some other element of the economic state $\Theta$. Proposition 4 also holds regardless of how the production side of the economy is specified, so long as Assumptions 1-8 are satisfied. As was the case for Proposition 3, the details of the production function and matching technology will generally affect the stochastic process for $\Theta_{t}$ and the functional form of $f$, but do not affect the conclusions of the proposition.

Although $l / u$ is the ratio of steady-state employment to unemployment, low $l / u$ is the standard way to model a recession in labor search models. Gross flows in and out of employment and unemployment are large in the U.S., so calibrated labor search models imply that employment and unemployment converge very rapidly to their steady state values, in a matter of weeks rather than quarters (e.g., Shimer, 2012; Elsby, Hobijn, and Şahin, 2013). Thus, the interpretation of low $l / u$ in Proposition 4 as a recession is typical.

Finally, the model's prediction that risk aversion is countercyclical is interesting because there is a great deal of empirical evidence that risk premia in financial markets are countercyclical (e.g., Fama and French, 1989; Campbell and Cochrane, 1999; Cochrane, 1999; Piazzesi and Swanson, 2008; Cooper and Priestley, 2009; Lettau and Ludvigson, 2010). Indeed, an important contribution of Campbell and Cochrane (1999) was to generate countercyclical risk aversion in an asset pricing model to better match the observed countercyclicality of risk premia in the data. Proposition 4 shows that labor market frictions provide an additional source of countercyclicality. In Campbell and Cochrane (1999), risk aversion is high in recessions because consumption is lower than its long-run history; here, risk aversion is higher in recessions because it's harder for households to offset shocks to their portfolios. I investigate the quantitative importance of this effect below. 


\subsection{Risk Aversion Is Higher for Households that Are Less Employable}

Propositions 3-4 and Corollary 2 all assumed a representative household. I now relax that assumption in order to consider the case where the economy is populated by a unit continuum of households divided into two types: a set of measure one of households of type 1, and a set of measure zero of households of type 2. Because the type 2 households are a set of measure zero, all of the aggregate variables in the economy are completely determined by the type 1 households, and so is the general equilbrium of the economy. Type 2 households are assumed to be the same as those of type 1 except that it is harder for them to find a job - that is, $f_{2}(\Theta)<f_{1}(\Theta)$ at the steady-state $\Theta$. (The aggregate state $\Theta$ is the same for both household types.)

Given that the aggregate equilibrium is determined by the type 1 households, it is straightforward to check that Propositions 1-4 continue to hold in this economy for both type 1 and type 2 households. In particular, Propositions 1 and 2 give the expressions for risk aversion for both type 1 and type 2 households, and the risk aversion of the two types of households can be compared using Proposition 3. Since $f_{2}(\Theta)<f_{1}(\Theta)$, Proposition 3 implies that $R_{2}^{c}\left(a_{2}, l_{2} ; \Theta\right)>R_{1}^{c}\left(a_{1}, l_{1} ; \Theta\right)$.

In other words, risk aversion is higher for less employable (type 2) households. These households face greater labor market frictions than those of type 1, so it is more difficult for them to insure themselves from asset fluctuations in the labor market, and they are correspondingly more risk averse. I explore the quantitative importance of this effect below.

Some examples of households that might fit the type 2, "less employable" classification are households with less education, households nearing retirement age, and households that suffer from discrimination in the labor market. According to the theory above, these households should be more risk averse than regular, type 1 households, and hold a smaller fraction of their wealth in risky assets such as stocks.

This result provides a formal justification for why households nearing retirement should hold a greater fraction of their wealth in bonds rather than stocks: they are more risk averse. ${ }^{35}$ Of course, households near retirement also have a greater fraction of their wealth in financial assets and less in human capital, so retirees have a greater need to diversify their financial holdings in order to diversify their total wealth. Bodie, Merton, and Samuelson (1992) solve a calibrated lifecycle portfolio allocation model numerically and find that labor market flexibility is an important

\footnotetext{
${ }^{35}$ Gollier (2002) notes that younger households should have lower absolute risk aversion because they can distribute a given fall in wealth over more periods of consumption. That effect is not present in the infinite-horizon model of the present paper, although it is present in the numerical analysis of Bodie et al. (1992).
} 
factor in the household's willingness to hold risky assets. For tractability, their analysis considers only the extreme cases of perfectly flexible and perfectly rigid labor markets, essentially the same two cases considered in Swanson (2012). The possibility that older households face greater labor market frictions than younger households is acknowledged by Bodie et al. (1992) as being potentially important, but is beyond the scope of their analysis. ${ }^{36}$ The present paper shows how their analysis can be extended to the case of frictional labor markets, and provides some immediate insights into the nature and magnitude of these effects.

\section{Empirical Evidence and Quantitative Implications}

The theoretical predictions of the model above are consistent with a large and growing body of empirical evidence. First, there is substantial evidence that households vary their labor supply in response to financial shocks. Imbens, Rubin, and Sacerdote (2001) estimate that individuals who win a prize in the Massachusetts state lottery reduce their earnings by about 11 cents for every dollar won. ${ }^{37}$ Cesarini, Lindqvist, Notowidigdo, and Östling (2017) corroborate and significantly extend this finding using administrative data on a large sample of Swedish lottery prize winners. They also find that individuals who win a lottery prize reduce their earnings by about 11 percent of unearned income won, and this effect rises to about 14 percent when spousal earnings are also included. Cesarini et al. (2017) also find that more than half this adjustment is along the intensive rather than extensive margin. Coronado and Perozek (2003) find that individuals who held more stocks in the late 1990s retired on average about 7 months earlier than nonstockholders. And Coile and Levine (2009) find that older individuals are about 7 percent less likely to retire in a given year after the stock market falls 30 percent. More generally, the labor supply literature consistently estimates a significant negative effect of unearned income on hours worked (e.g., Pencavel, 1986; Killingsworth and Heckman, 1986).

There is also substantial evidence that risk premia in financial markets are higher in re-

\footnotetext{
${ }^{36}$ For example, "The ability to vary labor supply ex post induces the individual to assume greater risks in his portfolio ex ante." (Bodie et al. 1992, p. 427); "Obviously, the opportunity to vary continuously one's labor supply without cost is a far cry from the workings of actual labor markets. A more realistic model would allow limited flexibility in varying labor and leisure." (ibid., p. 448); and "It is reasonable to hypothesize that, for most individuals, the degree of labor flexiliby diminishes over the life cycle. For this reason, the effective human capital on which the individual can draw also declines." (ibid., p. 446).

37 That is, if the prize is $\$ 10,000$ per year for 20 years, the typical prize winner reduces his or her earnings by $\$ 1100$ per year indefinitely, according to the Imbens et al. (2001) estimates. The prizes they study are each paid annually for 20 years.
} 
cessions (e.g., Fama and French, 1989; Cooper and Priestley, 2009). ${ }^{38}$ A natural explanation for this finding is that investors' risk aversion itself is higher in recessions - indeed, one of the contributions of Campbell and Cochrane (1999) was to provide a model that generates countercyclical risk aversion. Guiso, Sapienza, and Zingales (2017) provide direct evidence for countercyclical risk aversion using survey data from a large panel of Italian households before and during the 2008-09 recession. They show that these households' risk aversion is substantially higher during the recession and, importantly, that the increase in risk aversion is independent of the household's portfolio performance during the 2008 financial crisis. In other words, the increase in risk aversion appears to be unrelated to whether the household incurred portfolio losses or whether consumption fell below its previous ("habit") level, presenting a challenge for habit-based models of countercyclical risk aversion.

The simple, stylized model of the present paper is consistent with all of these basic empirical facts. The remainder of the section considers the international evidence and more detailed quantitative predictions of the model.

\subsection{International Comparison of Labor Flows and Household Portfolios}

Table 2 reports international evidence on labor market flows and household portfolio allocations across risky and safe assets. Hobijn and Şahin (2007) estimate average values of $s$ and $f(\Theta)$ over time for a variety of OECD countries, and values for the six largest countries in their sample are reported in the first two columns of Table $2 .{ }^{39}$ In the present paper, individuals may be out of the labor force, employed, or unemployed, so $s$ in Table 2 is defined to be the sum of the monthly flow rates from employment into unemployment and into nonemployment. The job-finding rate $f(\Theta)$ is the monthly flow rate from unemployment into employment. A striking feature of these estimates is that the job-finding rate in Continental Europe is an order of magnitude lower than in the U.S., ranging from 1.3 to 3.5 percent vs. more than 28 percent. By contrast, job separation rates are more similar across all the countries in the table.

The last three columns of Table 2 provide some statistics on portfolio allocations between risky and safe assets in each country. Data on the percentage of households owning equities is

\footnotetext{
38 See also Campbell and Cochrane (1999), Campbell (1999), Lettau and Ludvigson (2010), Piazzesi and Swanson (2008), and Cochrane and Piazzesi (2005).

39 Hobijn and Şahin (2007) estimate a job separation rate for the U.S. of .006. For consistency with Shimer's (2012) results for the U.S. reported later, I use Shimer's estimates for the U.S. in Table 2 (for which $s=.019$ and $f(\Theta)$ is the same as in Hobijn and Şahin (2007)).
} 
Table 2: International Comparison of Labor Flows and Household Portfolios

\begin{tabular}{|c|c|c|c|c|c|}
\hline & $s$ & $f(\Theta)$ & $\begin{array}{l}\text { percentage of } \\
\text { households } \\
\text { owning } \\
\text { equities } \\
\end{array}$ & $\begin{array}{c}\text { percentage of } \\
\text { households } \\
\text { owning risky } \\
\text { financial assets }\end{array}$ & $\begin{array}{l}\text { share of house- } \\
\text { hold portfolios } \\
\text { in currency } \\
\text { and deposits }\end{array}$ \\
\hline United States & .019 & .282 & 48.9 & 49.2 & 12.4 \\
\hline United Kingdom & .009 & .056 & 31.5 & 32.4 & 26.0 \\
\hline Germany & .006 & .035 & 18.9 & 25.1 & 33.9 \\
\hline France & .007 & .033 & - & - & 29.1 \\
\hline Spain & .012 & .020 & - & - & 38.1 \\
\hline Italy & .004 & .013 & 18.9 & 22.1 & 27.9 \\
\hline
\end{tabular}

Labor market flows $s$ and $f(\Theta)$ are from Hobijn and Şahin (2007, Table 4) and Shimer (2012); $s$ is sum of monthly flow rates from employment $(\mathrm{E})$ to unemployment $(\mathrm{U})$ and to nonemployment $(\mathrm{N}) ; f(\Theta)$ is monthly flow from $U$ to E. Percentages of households owning equities (directly and indirectly) and risky financial assets are from Guiso et al. (2002, Table I.5) and are upper bounds for the U.K., Germany, and Italy (ibid., p. 7). Share of household portfolios in currency and deposits is from Ynesta (2008, Table 1). See text for details.

from Guiso, Haliassos, and Japelli (2002) for the year 1998 and includes indirect holdings through mutual funds and retirement accounts as well as direct equity holdings. ${ }^{40}$ Data on the percentage of households holding risky financial assets (including corporate bonds as well as equities) is from the same source. The share of household portfolios in each country held in currency and deposits is from Ynesta (2008) for the year 2006.

The theme in the last three columns of Table 2 is that households in the U.S. are more likely to hold stocks and allocate a greater fraction of their portfolios to risky assets than households in the U.K. and Continental Europe. In fact, the difference between portfolio allocations in the U.S. and other countries in Table 2 are understatements because the U.K., German, and Italian data overestimate the degree of indirect stockholding in those countries, as discussed in the previous footnote. As shown by Guiso et al. (2002), these differences in portfolio holdings are robust to controlling for demographic characteristics such as household wealth or age; that is, U.S. households of a given wealth level and age are more likely to hold equities and risky financial assets than are European households of a similar wealth level and age.

The international evidence in Table 2 is thus consistent with the theoretical points raised earlier: Labor markets in Europe are more frictional than those in the U.S., and households in Europe are more risk averse in their portfolio allocations. There are, of course, other reasons

\footnotetext{
${ }^{40}$ Data for France and Spain are not available in the survey. Data on indirect equity holdings for the U.K., Germany, and Italy are upper bounds because the portfolio surveys for those countries do not provide information on the type of mutual funds held, so that indirect stockholding in these countries cannot be separated from indirect holdings of other assets (Guiso et al., 2002, p. 7).
} 
why European households might be more reluctant than U.S. households to invest in stocks; for example, stock markets in Europe are generally less liquid and more volatile than in the U.S., intermediation fees for indirect stock holding are typically higher, and the costs of acquiring financial information may be higher (Guiso and Jappelli, 2002, p. 260). But the lower liquidity and higher intermediation costs in European equity and mutual fund markets are also partly an equilibrium outcome of the lower level of household participation and activity in those markets. Thus, it is not clear that these other factors are fundamental causes of low equity market participation, as opposed to an endogenous response to European households' apparently higher risk aversion and preference for holding safer assets. Thus, it is certainly possible that this apparently higher level of risk aversion is due in part to the greater labor market rigidity faced by European households.

\subsection{Quantitative Implications of Labor Market Frictions for Risk Aversion}

In Table 3, I consider the quantitative importance of these labor market differences for risk aversion across countries. The first two rows report results for the benchmark cases of perfect labor market rigidity and perfect flexibility, essentially corresponding to the two extreme cases considered in Swanson (2012). The first two columns report the corresponding values of $s$ and $f(\Theta)$, while the third colum reports the ratio $(s+f(\Theta)) /(r+s+f(\Theta))$, which lies between 0 and 1 and can be thought of as an index of labor market flexibility, as discussed earlier. ${ }^{41}$ For the monthly discount rate $r$, I use Hall's (2017), estimate of 0.7 percent per month, based on the similarity between firms' investment in "match capital" in the labor market and other types of capital like physical plant and equipment. This similarity implies that discount rates in the labor market should be relatively high and volatile, just as they are in the capital markets.

The last four columns of Table 3 report the value of relative risk aversion $R^{c}$ from equation (40) for different values of the utility curvature parameters $\gamma$ and $\chi$. When labor markets are perfectly rigid, $R^{c}=\gamma$, while when labor markets are perfectly flexible, $R^{c}$ is smaller by a factor of three to ten for the parameterizations in the table, a dramatic difference.

The rest of Table 3 focuses on frictional labor markets, calibrated to the international values from Hobijn and Şahin (2007) in Table 2. For the U.S., the labor market flexibility index is .977 , virtually as high as the frictionless benchmark. The values for the European country

\footnotetext{
41 The benchmark $s=f(\Theta)=1$ yields a labor market flexibility index of .997, which is slightly less than 1 . One cannot generate an index value higher than this without assuming a lower value for $r$.
} 
Table 3: Quantitative Importance of Labor Market Frictions for Risk Aversion

$$
\begin{array}{cccccc} 
& & \multicolumn{4}{c}{\text { Relative Risk Aversion } R^{c}} \\
& & \gamma=2 & \gamma=5 & \gamma=10 & \gamma=20 \\
s \quad f(\Theta) & \frac{s+f(\Theta)}{r+s+f(\Theta)} & \chi=1.5 & \chi=0.5 & \chi=2.5 & \chi=10 \\
\hline
\end{array}
$$

Theoretical labor market benchmarks:

$\begin{array}{lccccccc}\text { perfect rigidity } & 0 & 0 & 0 & 2 & 5 & 10 & 20 \\ \text { perfect flexibility } & 1 & 1 & .997 & 0.86 & 0.46 & 2.01 & 6.68 \\ \text { ternational comparison: } & & & & & & & \\ \text { United States } & .019 & .282 & .977 & 0.87 & 0.46 & 2.04 & 6.77 \\ \text { United Kingdom } & .009 & .056 & .903 & 0.91 & 0.50 & 2.17 & 7.13 \\ \text { Germany } & .006 & .035 & .854 & 0.94 & 0.52 & 2.26 & 7.38 \\ \text { France } & .007 & .033 & .851 & 0.94 & 0.53 & 2.27 & 7.40 \\ \text { Spain } & .012 & .020 & .821 & 0.96 & 0.54 & 2.34 & 7.57 \\ \text { Italy } & .004 & .013 & .708 & 1.03 & 0.62 & 2.61 & 8.28\end{array}$

Relative risk aversion $R^{c}$ from equation (40) for different values of $\gamma, \chi$, and $r$, using estimated values of $s$ and $f(\Theta)$ from Hobijn and Şahin (2007) and Shimer (2012) and $r=.007$ from Hall (2017). See notes to Table 2 and text for details.

calibrations are lower, but even Italy's labor market flexibility index is about 71 percent by this metric. Intuitively, households in the model are sufficiently patient that the extra time it takes to vary employment is not extremely costly; thus, even households in the most rigid calibrations in Table 3 are able to insure themselves from asset fluctuations to some extent in the labor market.

These observations are reflected in the implied relative risk aversion coefficients $R^{c}$ in the last four columns of Table 3. Each of these four columns considers a different configuration of utility curvature parameters $\gamma$ and $\chi$. For all of these parameter configurations, relative risk aversion in the U.S. is very close to the frictionless benchmark and never near the traditional, fixed-labor measure. For the other countries, frictional labor markets cause risk aversion to be higher, ranging from a few percent higher in the U.K. to up to 35\% higher for Italy. Thus, differences in labor market frictions can account for a quantitatively significant part of the apparent differences in risk aversion in Table 2. Note, though, that even for the most rigid countries in Table 3, the implied coefficients of relative risk aversion are still much lower than the traditional, fixed-labor benchmark.

In fact, the risk aversion estimates in Table 3 are likely to represent underestimates of the true quantitative effect of labor market frictions on risk aversion. In the stylized model of the present paper, the only cost of labor market frictions is the delay in labor market adjustment, and this cost is completely characterized by the parameter $r$. To the extent that this delay is 
made more costly by borrowing constraints, depreciation of human capital, or stigma associated with longer unemployment, the cost parameter $r$ should be taken to be higher than 0.7 percent for the purposes of the calculations in Table 3. If we take $r=.014$ instead of .007 , then the risk aversion coefficients for the U.S. are still very cose to those in Table 3, but the coefficients for the more frictional countries increase by another roughly $20 \%$ (not reported in the table).

\subsection{Quantitative Implications for Cyclical Variation in Risk Aversion}

Finally, I consider whether labor market frictions can make a quantitatively significant contribution to business cycle variation in risk aversion. Recall that risk aversion may be higher in recessions simply because household consumption is lower and marginal utility is higher, as in Campbell and Cochrane (1999) and Swanson (2012, 2018). In this section, I investigate whether labor market frictions play an additional role contributing to this variation. The job separation rate is higher and the job finding rate lower in recessions, implying that the labor market is correspondingly less flexible. A less flexible labor market implies that risk aversion should be higher, all else equal, in addition to any effects coming from the decline in consumption.

The first two rows of Table 4 report parameters calibrated to the U.S. economy in expansions and recessions. Values of $s$ and $f(\Theta)$ are taken from Shimer (2012), while estimates of $r$ are from Hall (2017). ${ }^{42}$ In recessions, the job separation rate increases by almost a third, the job finding rate falls by $40 \%$, and the discount rate roughly triples. Nevertheless, labor markets are so flexible in the U.S. that even in the recession calibration, the index of labor market flexibility remains very high, .953. The resulting differences in risk aversion $R^{c}$ between recessions and expansions in the last four columns are thus quite small. ${ }^{43}$ Intuitively, labor market flows in the U.S. are simply too large to make delay very costly for households, even in recessions.

Of course, this cyclical variation tends to be larger in countries with more rigid labor markets. In the bottom panel of Table 4, I consider a calibration based on the estimates for Italy in Table 3. In particular, I take the job separation rate for the U.S. in expansions from Table 4 and scale those values down by the ratio of average job separations in Italy to that in the U.S.

\footnotetext{
${ }^{42}$ Hall (2017) estimates a one-month discount rate of -0.1 percent in expansions and 13.5 percent in recessions, and an annualized 29-month discount rate of 4.4 percent in expansions and 12.2 percent in recessions (where 29 months corresponds to the lifetime of a job in the model). In my application, the relevant period is the lifetime of the unemployment spell rather than the job, and the former is shorter than the latter. Thus, in Table 4 I use discount rates that are intermediate between Hall's one-month and 29-month values.

43 Note that these computations set consumption to its steady-state value, so the differences between expansion and recession in Table 4 are completely due to differences in labor market rigidity.
} 
Table 4: Quantitative Implications for Cyclical Variation in Risk Aversion Relative Risk Aversion $R^{c}$

\begin{tabular}{|c|c|c|c|c|c|c|c|c|}
\hline & $s$ & $f(\Theta)$ & $r$ & $\frac{s+f(\Theta)}{r+s+f(\Theta)}$ & $\begin{array}{c}\gamma=2 \\
\chi=1.5\end{array}$ & $\begin{array}{c}\gamma=5 \\
\chi=0.5\end{array}$ & $\begin{aligned} \gamma & =10 \\
\chi & =2.5\end{aligned}$ & $\begin{array}{l}\gamma=20 \\
\chi=10\end{array}$ \\
\hline U.S., expansion & .017 & .35 & .003 & .995 & 0.86 & 0.46 & 2.01 & 6.70 \\
\hline U.S., recession & .022 & .20 & .011 & .953 & 0.88 & 0.47 & 2.08 & 6.88 \\
\hline rigid labor mkt, expans. & .0036 & .016 & .003 & .868 & 0.93 & 0.52 & 2.24 & 7.31 \\
\hline rigid labor mkt, recess. & .0046 & .009 & .011 & .557 & 1.15 & 0.76 & 3.10 & 9.45 \\
\hline
\end{tabular}

Relative risk aversion $R^{c}$ from equation (40) for different values of $\gamma, \chi$, and $r$. U.S. values of $s$ and $f(\Theta)$ are from Shimer (2012), $r$ from Hall (2017). See notes to Table 3 and text for details.

from Table 3. This produces a separation rate of 0.36 percent in expansions and 0.46 percent in recessions. I do the same thing for the job finding rate. Finally, I assume that the discount rate is the same as in the U.S. calibration. (I refer to this as a "rigid labor market" rather than an "Italy" calibration because I don't have actual data on how job separation and finding rates vary over the business cycle in Italy.) In these bottom rows, the variation in risk aversion over the business cycle is much more significant, rising about $25-50 \%$ in recessions.

I conclude from this exercise that cyclical variation in labor market frictions is probably not a significant contributor to time-varying risk aversion in the U.S., but it may be a significant contributor to the cyclicality of risk aversion in countries with more frictional labor markets, such as in Continental Europe.

\subsection{Other International Evidence}

Campbell (1999) reports cross-country comparisons of consumption volatility and the equity premium for a variety of countries from 1970-1996, which was the longest sample available to him for the non-U.S. countries at the time (using quarterly MSCI data). Over this sample, consumption growth in the U.S. has an annualized standard deviation of about 0.9 percent, vs. 2.6 percent in the U.K., 2.1 percent in France, 2.5 percent in Germany, 1.7 percent in Italy, 2.8 percent in the Netherlands, 1.9 percent in Sweden, and 2.2 percent in Switzerland (Table 3 of Campbell). Thus, consumption is about twice as volitile in Europe as in the U.S. over this period, consistent with the model in the present paper. Intuitively, a more frictional labor market implies that economic shocks must pass through more to consumption.

Over the same period, 1970-96, the equity premium in the U.S. was $4.5 \%$, while the equity premium in the U.K. was $6.2 \%$, France $4.5 \%$, Germany $4.8 \%$, the Netherlands $9.0 \%$, Sweden $6.4 \%$, 
Switzerland 10.1\%, and Italy $-1.5 \%$ (Table 2 of Campbell). Other than Italy, which is a large outlier presumably due to poor economic performance during this period, the equity premium is higher in all of these countries than in the U.S. (although it's about the same in France). Again, these results are consistent with the predictions of the model in the present paper. A more frictional labor market implies that households should be more risk averse, leading to a higher equity premium. Of course, the equity premium in a country also depends on many other factors than labor market frictions (as evidenced by Italy), but the fact that Campbell's findings go in the direction predicted by the simple model here is noteworthy.

\section{Conclusions}

Traditional studies of risk aversion, such as Arrow (1964), Pratt (1965), Epstein and Zin (1989), and Weil (1989), assume that household labor supply is fixed. However, this assumption ignores households' ability to partially offset portfolio shocks by varying hours of work. As a result, fixed-labor measures of risk aversion are not representative of the household's aversion to holding risky assets when labor supply can vary. For reasonable parameterizations, traditional, fixedlabor measures of risk aversion can overstate the household's aversion to holding a risky asset by a factor of as much as ten, as in Table 3 .

The closed-form expressions for risk aversion I derive above lie between the traditional, fixed-labor measures and the flexible-labor expressions in Swanson (2012). Traditional, fixedlabor measures of risk aversion are essentially unrelated to the equity premium in a standard real business cycle model with labor market search, while the expressions derived here match the equity premium closely. Thus, taking into account the household's labor margin is necessary for risk aversion to correspond to risk premia in the model.

According to my analysis, household risk aversion is higher: 1) in countries with more frictional labor markets, such as Continental Europe, 2) in recessions, and 3) for households that are less employable, such as less-educated households, retirees, and households facing labor market discrimination. In all of these cases, it's more difficult for the household to vary hours of work in response to portfolio shocks, and so these shocks pass through to consumption to a greater extent.

These predictions are consistent with a wide variety of empirical evidence in the literature. Numerous authors find that Continental European households are more conservative in their 
portfolio allocations (e.g., Guiso et al., 2002), that risk premia are higher in recessions (e.g., Fama and French, 1989), and that older households invest more conservatively (e.g., Guiso et al., 2002). Many other authors find that households vary their labor supply significantly in response to asset fluctuations (e.g., Imbens et al., 2001; Cesarini et al., 2017).

Quantitatively, U.S. labor market flows are sufficiently high that household risk aversion is very close to the frictoinless benchmark considered in Swanson (2012). More rigid labor markets, such as Spain and Italy, imply a higher coefficient of relative risk aversion, which I conservatively estimate to be 15-35\% larger than the frictionless benchmark. Note that even these higher values are still substantially less than traditional, fixed-labor measure of risk aversion. Thus, taking the household's labor margin into account is important for understanding the household's attitudes toward holding a risky asset. 


\section{Appendix: Proofs of Propositions and Technical Details}

\section{Microfoundation for Household Preferences}

The household consists of a unit continuum of individuals, indexed by $i \in[0,1]$. At each time $t$, each individual either works, searches for a job, or engages in home production of nonmarket goods and services, including "leisure". Let $l_{t}$ denote the measure of household members who work in period $t, u_{t}$ the measure of household members who search, and $h_{t}=1-l_{t}-u_{t}$ the measure of household members who engage in home production. The household's output of nonmarket goods and services, $c_{t}^{n}$, is given by

$$
c_{t}^{n}=H\left(h_{t}\right),
$$

where $H$ is an increasing, concave, twice-differentiable function of the measure of household members engaged in home production.

Each individual household member has a period utility function given by

$$
u\left(c_{i t}^{m}\right)+v\left(c_{i t}^{n}\right)
$$

where $c_{i t}^{m}$ and $c_{i t}^{n}$ denotes individual $i$ 's consumption at time $t$ of market and nonmarket goods, respectively, and $u$ and $v$ are increasing, strictly concave, and twice-differentiable functions. For simplicity, I assume that the disutility of working, searching, and home production are equal and enter additively into (A2). Since the disutility of work then equals a constant for each individual in each period $t$, that constant can be normalized to zero.

Household members pool their income and consumption of home-produced goods, so that each member consumes the same amount of market and nonmarket goods in each period $t$. Let $c_{t}$ and $c_{t}^{n}$ denote this common level of market and nonmarket good consumption, respectively.

The household's utility flow in each period $t$ is given by the integral of its individual members' utility flows, which equals

$$
u\left(c_{t}\right)+v\left(H\left(1-l_{t}-u_{t}\right)\right)
$$

since each individual's consumption of market and nonmarket goods is the same. Let $U\left(c_{t}\right) \equiv u\left(c_{t}\right)$ and $V\left(l_{t}+u_{t}\right) \equiv-v\left(H\left(1-l_{t}-u_{t}\right)\right)$. Then the household's period utility function is given by

$$
U\left(c_{t}\right)-V\left(l_{t}+u_{t}\right),
$$

where $U$ is increasing, strictly concave, and twice-differentiable, and $V$ is increasing, strictly convex, and twice-differentiable, as stated in preference specification (1).

\section{Proof of Proposition 1}

Since $\left(a_{t}, l_{t} ; \Theta_{t}\right)$ is an interior point of $X, \mathbb{V}\left(a_{t}+\frac{\sigma \underline{\varepsilon}}{1+r_{t}}, l_{t} ; \Theta_{t}\right)$ and $\mathbb{V}\left(a_{t}+\frac{\sigma \bar{\varepsilon}}{1+r_{t}}, l_{t} ; \Theta_{t}\right)$ exist for sufficiently

small $\sigma$, and $\mathbb{V}\left(a_{t}+\frac{\sigma \varepsilon}{1+r_{t}}, l_{t} ; \Theta_{t}\right) \leq \widetilde{\mathbb{V}}\left(a_{t}, l_{t} ; \Theta_{t} ; \sigma\right) \leq \mathbb{V}\left(a_{t}+\frac{\sigma \bar{\varepsilon}}{1+r_{t}}, l_{t} ; \Theta_{t}\right)$, hence $\widetilde{\mathbb{V}}\left(a_{t}, l_{t} ; \Theta_{t} ; \sigma\right)$ exists. Moreover, since $\mathbb{V}(\cdot, \cdot ; \cdot)$ is continuous and increasing in its first argument, the intermediate value theorem implies there exists a unique $-\mu\left(a_{t}, l_{t} ; \Theta_{t} ; \sigma\right) \in[\sigma \underline{\varepsilon}, \sigma \bar{\varepsilon}]$ satisfying $\mathbb{V}\left(a_{t}-\frac{\mu}{1+r_{t}}, l_{t} ; \Theta_{t}\right)=\widetilde{\mathbb{V}}\left(a_{t}, l_{t} ; \Theta_{t} ; \sigma\right)$.

For a sufficiently small fee $\mu$ in (8), the change in household welfare (6) is given to first order by

$$
\frac{-\mathbb{V}_{1}\left(a_{t}, l_{t} ; \Theta_{t}\right)}{1+r_{t}} d \mu
$$

Using the envelope theroem, we can rewrite (A5) as

$$
-\beta E_{t} \mathbb{V}_{1}\left(a_{t+1}^{*}, l_{t+1}^{*} ; \Theta_{t+1}\right) d \mu,
$$

where $a_{t+1}^{*} \equiv\left(1+r_{t}\right) a_{t}+w_{t} l_{t}+d_{t}-c_{t}^{*}$ and $l_{t+1}^{*}=(1-s) l_{t}+f\left(\Theta_{t}\right) u_{t}^{*}$.

Turning now to the gamble in (7), note that the household's optimal choices for consumption and unemployment in period $t, c_{t}^{*}$ and $u_{t}^{*}$, will generally depend on the size of the gamble $\sigma$-for example, the household may undertake precautionary saving when faced with this gamble. Thus, in this section we 
write $c_{t}^{*} \equiv c^{*}\left(a_{t}, l_{t} ; \Theta_{t} ; \sigma\right)$ and $u_{t}^{*} \equiv u^{*}\left(a_{t}, l_{t} ; \Theta_{t} ; \sigma\right)$ to emphasize this dependence on $\sigma$. The household's value function, inclusive of the one-shot gamble in (7), satisfies

$$
\widetilde{\mathbb{V}}\left(a_{t}, l_{t} ; \Theta_{t} ; \sigma\right)=U\left(c_{t}^{*}\right)-V\left(l_{t}+u_{t}^{*}\right)+\beta E_{t} \mathbb{V}\left(a_{t+1}^{*}, l_{t+1}^{*} ; \Theta_{t+1}\right) .
$$

Because (7) describes a one-shot gamble in period $t$, it affects assets $a_{t+1}^{*}$ and $l_{t+1}^{*}$ in period $t+1$ but otherwise does not affect the household's optimization problem from period $t+1$ onward; as a result, the household's value-to-go at time $t+1$ is just $\mathbb{V}\left(a_{t+1}^{*}, l_{t+1}^{*} ; \Theta_{t+1}\right)$, which does not depend on $\sigma$ except through $a_{t+1}^{*}$ and $l_{t+1}^{*}$.

Differentiating (A7) with respect to $\sigma$, the first-order effect of the gamble on household welfare is

$$
\left[U^{\prime} \frac{\partial c_{t}^{*}}{\partial \sigma}-V^{\prime} \frac{\partial u_{t}^{*}}{\partial \sigma}+\beta E_{t} \mathbb{V}_{1} \cdot\left(-\frac{\partial c_{t}^{*}}{\partial \sigma}+\varepsilon_{t+1}\right)+\beta E_{t} \mathbb{V}_{2} f\left(\Theta_{t}\right) \frac{\partial u_{t}^{*}}{\partial \sigma}\right] d \sigma
$$

where the arguments of $U^{\prime}, V^{\prime}, \mathbb{V}_{1}$, and $\mathbb{V}_{2}$ are suppressed to reduce notation. Optimality of $c_{t}^{*}$ and $u_{t}^{*}$ implies that the terms involving $\partial c_{t}^{*} / \partial \sigma$ and $\partial u_{t}^{*} / \partial \sigma$ in (A8) cancel, as in the usual envelope theorem (these derivatives vanish at $\sigma=0$ anyway, for the reasons discussed below). Moreover, $E_{t} \mathbb{V}_{1}\left(a_{t+1}^{*}, l_{t+1}^{*} ; \Theta_{t+1}\right) \varepsilon_{t+1}=0$ because $\varepsilon_{t+1}$ is independent of $\Theta_{t+1}, l_{t+1}^{*}$, and $a_{t+1}^{*}$, evaluating the latter two at $\sigma=0$. Thus, the first-order cost of the gamble is zero, as in Arrow (1964) and Pratt (1965).

To second order, the effect of the gamble on household welfare is

$$
\begin{aligned}
& {\left[U^{\prime \prime}\left(\frac{\partial c_{t}^{*}}{\partial \sigma}\right)^{2}-V^{\prime \prime}\left(\frac{\partial u_{t}^{*}}{\partial \sigma}\right)^{2}+U^{\prime} \frac{\partial^{2} c_{t}^{*}}{\partial \sigma^{2}}-V^{\prime} \frac{\partial^{2} u_{t}^{*}}{\partial \sigma^{2}}\right.} \\
& \quad+\beta E_{t} \mathbb{V}_{11} \cdot\left(-\frac{\partial c_{t}^{*}}{\partial \sigma}+\varepsilon_{t+1}\right)^{2}+\beta E_{t} \mathbb{V}_{12} \cdot\left(-\frac{\partial c_{t}^{*}}{\partial \sigma}+\varepsilon_{t+1}\right) f\left(\Theta_{t}\right) \frac{\partial u_{t}^{*}}{\partial \sigma}+\beta E_{t} \mathbb{V}_{1} \cdot\left(-\frac{\partial^{2} c_{t}^{*}}{\partial \sigma^{2}}\right) \\
& \left.\quad+\beta E_{t} \mathbb{V}_{22} f\left(\Theta_{t}\right)^{2}\left(\frac{\partial u_{t}^{*}}{\partial \sigma}\right)^{2}+\beta E_{t} \mathbb{V}_{12} \cdot\left(-\frac{\partial c_{t}^{*}}{\partial \sigma}+\varepsilon_{t+1}\right) f\left(\Theta_{t}\right) \frac{\partial u_{t}^{*}}{\partial \sigma}+\beta E_{t} \mathbb{V}_{2} f\left(\Theta_{t}\right) \frac{\partial^{2} u_{t}^{*}}{\partial \sigma^{2}}\right] \frac{d \sigma^{2}}{2}
\end{aligned}
$$

The terms involving $\partial^{2} c_{t}^{*} / \partial \sigma^{2}$ and $\partial^{2} u_{t}^{*} / \partial \sigma^{2}$ cancel due to the optimality of $c_{t}^{*}$ and $u_{t}^{*}$. The derivatives $\partial c_{t}^{*} / \partial \sigma$ and $\partial u_{t}^{*} / \partial \sigma$ also vanish at $\sigma=0$ (there are two ways to see this: first, the linearized version of the model is certainty equivalent; alternatively, if $\varepsilon$ is symmetric, the gamble in (7) is isomorphic for positive and negative $\sigma$, hence $c^{*}$ and $u^{*}$ must be symmetric about $\sigma=0$, implying the derivatives vanish). Thus, for infinitesimal gambles, (A9) simplifies to

$$
\beta E_{t} \mathbb{V}_{11}\left(a_{t+1}^{*}, l_{t+1}^{*} ; \Theta_{t+1}\right) \varepsilon_{t+1}^{2} \frac{d \sigma^{2}}{2}
$$

Finally, $\varepsilon_{t+1}$ is independent of $\Theta_{t+1}, l_{t+1}^{*}$, and $a_{t+1}^{*}$, evaluating the latter two at $\sigma=0$. Since $\varepsilon_{t+1}$ has unit variance, (A10) reduces to

$$
\beta E_{t} \mathbb{V}_{11}\left(a_{t+1}^{*}, l_{t+1}^{*} ; \Theta_{t+1}\right) \frac{d \sigma^{2}}{2} .
$$

Equating (A6) to (A11) allows us to solve for $d \mu$ as a function of $d \sigma^{2}$. Thus, $\lim _{\sigma \rightarrow 0} 2 \mu\left(a_{t}, l_{t} ; \Theta_{t} ; \sigma\right) / \sigma^{2}$ exists and is given by

$$
\frac{-E_{t} \mathbb{V}_{11}\left(a_{t+1}^{*}, l_{t+1}^{*} ; \Theta_{t+1}\right)}{E_{t} \mathbb{V}_{1}\left(a_{t+1}^{*}, l_{t+1}^{*} ; \Theta_{t+1}\right)}
$$

To evaluate (A12) at the nonstochastic steady state, set $a_{t+1}=a, l_{t+1}=l$, and $\Theta_{t+1}=\Theta$ to get

$$
\frac{-\mathbb{V}_{11}(a, l ; \Theta)}{\mathbb{V}_{1}(a, l ; \Theta)}
$$




\section{Proof of Lemma 1}

The computation in the lemma is performed in two steps, using the household's Euler equation for unemployment,

$$
\frac{V^{\prime}\left(l_{\tau}^{*}+u_{\tau}^{*}\right)}{f\left(\Theta_{\tau}\right)}=\beta E_{\tau}\left[w_{\tau+1} U^{\prime}\left(c_{\tau+1}^{*}\right)-V^{\prime}\left(l_{\tau+1}^{*}+u_{\tau+1}^{*}\right)+(1-s) \frac{V^{\prime}\left(l_{\tau+1}^{*}+u_{\tau+1}^{*}\right)}{f\left(\Theta_{\tau+1}\right)}\right],
$$

and the transition equation (2) for labor. Equation (A14) is derived in the same way as the consumption Euler equation and is standard in the labor search literature. The left-hand side of (A14) represents the household's marginal cost of finding a job, while the right-hand side is the discounted marginal benefit of having one more employed worker, given by the wage times the marginal utility of consumption less the marginal disutility of work, plus the job retention rate $(1-s)$ times the marginal benefit of not having to search for a job next period.

Equation (A14) holds at each date $\tau \geq t$ for any initial asset stock $a_{t}$. Differentiating (A14) with respect to $a_{t}$ and taking time- $t$ expectations yields

$$
\begin{aligned}
E_{t} \frac{V^{\prime \prime}\left(l_{\tau}^{*}+u_{\tau}^{*}\right)}{f\left(\Theta_{\tau}\right)}\left(\frac{\partial l_{\tau}^{*}}{\partial a_{t}}+\frac{\partial u_{\tau}^{*}}{\partial a_{t}}\right)=\beta E_{t}[ & w_{\tau+1} U^{\prime \prime}\left(c_{\tau+1}^{*}\right) \frac{\partial c_{\tau+1}^{*}}{\partial a_{t}} \\
& \left.+V^{\prime \prime}\left(l_{\tau+1}^{*}+u_{\tau+1}^{*}\right) \frac{1-s-f\left(\Theta_{\tau+1}\right)}{f\left(\Theta_{\tau+1}\right)}\left(\frac{\partial l_{\tau+1}^{*}}{\partial a_{t}}+\frac{\partial u_{\tau+1}^{*}}{\partial a_{t}}\right)\right] .
\end{aligned}
$$

Evaluating (A15) at steady state gives

$$
E_{t}\left(\frac{\partial l_{\tau}^{*}}{\partial a_{t}}+\frac{\partial u_{\tau}^{*}}{\partial a_{t}}\right)=\beta w \frac{U^{\prime \prime}(c) f(\Theta)}{V^{\prime \prime}(l+u)} E_{t} \frac{\partial c_{\tau+1}^{*}}{\partial a_{t}}+\beta(1-s-f(\Theta)) E_{t}\left(\frac{\partial l_{\tau+1}^{*}}{\partial a_{t}}+\frac{\partial u_{\tau+1}^{*}}{\partial a_{t}}\right) .
$$

Substituting for $\partial c_{\tau+1}^{*} / \partial a_{t}$ from (15), and for $w$ from (A14) evaluated at steady state, this becomes

$$
E_{t}\left(\frac{\partial l_{\tau}^{*}}{\partial a_{t}}+\frac{\partial u_{\tau}^{*}}{\partial a_{t}}\right)=-\frac{\gamma}{\chi} \frac{l+u}{c}[1-\beta(1-s-f(\Theta))] \frac{\partial c_{t}^{*}}{\partial a_{t}}+\beta(1-s-f(\Theta)) E_{t}\left(\frac{\partial l_{\tau+1}^{*}}{\partial a_{t}}+\frac{\partial u_{\tau+1}^{*}}{\partial a_{t}}\right),
$$

where $\gamma \equiv-c U^{\prime \prime}(c) / U^{\prime}(c)$ and $\chi \equiv(l+u) V^{\prime \prime}(l+u) / V^{\prime}(l+u)$. Since $|1-s-f(\Theta)|<1$, equation (A17) can be solved forward to yield

$$
E_{t}\left(\frac{\partial l_{\tau}^{*}}{\partial a_{t}}+\frac{\partial u_{\tau}^{*}}{\partial a_{t}}\right)=-\frac{\gamma}{\chi} \frac{l+u}{c} \frac{\partial c_{t}^{*}}{\partial a_{t}}
$$

In response to a change in assets, household leisure $\left(1-l_{t}-u_{t}\right)$ and consumption move in the same direction. (Intuitively, it is natural to think of both consumption and leisure as normal goods, so that $\partial c_{t}^{*} / \partial a_{t}>0$ and $\partial\left(l_{t}^{*}+u_{t}^{*}\right) / \partial a_{t}<0$, although this sign restriction is not required below.)

The transition equation (2) for labor implies

$$
E_{t} \frac{\partial l_{t+k}^{*}}{\partial a_{t}}=(1-s) E_{t} \frac{\partial l_{t+k-1}^{*}}{\partial a_{t}}+f\left(\Theta_{t+k-1}\right) E_{t} \frac{\partial u_{t+k-1}^{*}}{\partial a_{t}} .
$$

Evaluating (A19) at steady state and applying (A18) gives

$$
E_{t} \frac{\partial l_{t+k}^{*}}{\partial a_{t}}=(1-s-f(\Theta)) E_{t} \frac{\partial l_{t+k-1}^{*}}{\partial a_{t}}-\frac{\gamma}{\chi} \frac{l+u}{c} f(\Theta) \frac{\partial c_{t}^{*}}{\partial a_{t}} .
$$

Solving (A20) backward to the initial condition $\partial l_{t} / \partial a_{t}=0$ gives

$$
E_{t} \frac{\partial l_{t+k}^{*}}{\partial a_{t}}=-\frac{\gamma}{\chi} \frac{l+u}{c} \frac{f(\Theta)}{s+f(\Theta)}\left[1-(1-s-f(\Theta))^{k}\right] \frac{\partial c_{t}^{*}}{\partial a_{t}} .
$$




\section{Relationship between the Stochastic Discount Factor, Risk Premia, and Risk Aversion}

The household's aversion to gambles over asset values depends on its ability to offset the outcome of those gambles with changes in hours worked. Here, the analysis is extended to show the relationship between risk aversion and risk premia in the Lucas-Breeden stochastic discounting framework. Risk premia in this framework are closely related to the definition of risk aversion in the present paper, and are generally unrelated to traditional, fixed-labor measures of risk aversion.

Let $p_{t}^{i}$ denote the ex-dividend time- $t$ price of an asset $i$ that pays stochastic dividend $d_{t}^{i}$ each period. In equilibrium, $p_{t}^{i}$ satisfies

$$
p_{t}^{i}=E_{t} m_{t+1}\left(d_{t+1}^{i}+p_{t+1}^{i}\right),
$$

where $m_{t+1} \equiv \beta U^{\prime}\left(c_{t+1}\right) / U^{\prime}\left(c_{t}\right)$ denotes the household's stochastic discount factor.

Let $1+r_{t+1}^{i}$ denote the realized gross return on the asset,

$$
1+r_{t+1}^{i} \equiv \frac{d_{t+1}^{i}+p_{t+1}^{i}}{p_{t}^{i}}
$$

and define the risk premium on the asset, $\psi_{t}^{i}$, to be its expected excess return,

$$
\psi_{t}^{i} \equiv E_{t} r_{t+1}^{i}-r_{t+1}^{f},
$$

where $1+r_{t+1}^{f} \equiv 1 / E_{t} m_{t+1}$ denotes the risk-free rate. Then

$$
\begin{aligned}
\psi_{t}^{i} & =\frac{E_{t} m_{t+1} E_{t}\left(d_{t+1}^{i}+p_{t+1}^{i}\right)-E_{t} m_{t+1}\left(d_{t+1}^{i}+p_{t+1}^{i}\right)}{p_{t}^{i} E_{t} m_{t+1}} \\
& =\frac{-\operatorname{Cov}_{t}\left(m_{t+1}, r_{t+1}^{i}\right)}{E_{t} m_{t+1}}
\end{aligned}
$$

where $\operatorname{Cov}_{t}$ denotes the covariance conditional on information at time $t$.

Conditional on information at time $t$, the household's stochastic discount factor can be written to first order as

$$
d m_{t+1}=-\frac{\beta \gamma}{c} d c_{t+1}^{*},
$$

where $\gamma \equiv c U^{\prime \prime} / U^{\prime}$. The first-order change in consumption, $d c_{t+1}^{*}$, in turn can be computed from the household's Euler equation and budget constraint, where it is now recognized that $w_{t}, r_{t}, d_{t}$, and $\Theta_{t}$ may vary in response to economic shocks. This computation is summarized in the following lemma:

Lemma A1. Let $\varphi \equiv \frac{s+f(\Theta)}{r+s+f(\Theta)}$, and let $\lambda \equiv \frac{\gamma}{\chi} \frac{l}{c}$, the long-run sensitivity of labor relative to consumption in response to a change in assets. To first order, evaluated at steady state,

$$
\begin{aligned}
& d c_{t+1}^{*}=\frac{r}{1+w \lambda \varphi}\left[d a_{t+1}+\frac{w}{r+s+f(\Theta)} d l_{t+1}\right. \\
& \left.\quad+E_{t+1} \sum_{k=1}^{\infty} \frac{1}{(1+r)^{k}}\left(l d w_{t+k}+d d_{t+k}+a d r_{t+k}+\frac{w}{r+s+f(\Theta)} u d f_{t+k}\right)\right] \\
& \quad-\frac{c}{\gamma} E_{t+1} \sum_{k=1}^{\infty} \frac{1}{(1+r)^{k}}\left(\beta d r_{t+k+1}-\frac{r w \lambda \varphi}{1+w \lambda \varphi} d \omega_{t+k}\right)
\end{aligned}
$$

where $d f_{t+k}$ denotes the first-order change in the job-finding rate $f\left(\Theta_{t+k}\right)$ and $d \omega_{t+k}$ denotes the first-order change in the return to searching for a job at time $t+k$, defined in the Appendix.

Proof: See below. 
Note that if $w, r, d$, and $f(\Theta)$ do not change, as in the Arrow-Pratt gamble for a single household in Section 3, then equation (A27) reduces to (25), where $d l_{t}=0$ in that example because labor at time $t$ is given. More generally, (A27) includes the effects of changes in $w, r, d$, and $f(\Theta)$ on consumption. The term in square brackets in (A27) describes the change in household wealth-including nonfinancial wealth - and thus the first line of (A27) describes the wealth effect on consumption. The last line of (A27) describes the substitution effect: changes in consumption due to changes in current and future wages and interest rates. The ratio $\frac{w}{r+s+f(\Theta)}$ corresponds to the present discounted value of wages from an increase in labor at time $t$, over the lifetime of the job. The term $u d f_{t+k}$, which represents the change in the number of jobs found each period, is multiplied by the same present value.

Let $d \hat{A}_{t+1}$ denote the quantity inside the square brackets in (A27), representing the change in household wealth, and let $d \Phi_{t+1} \equiv E_{t+1} \sum_{k=1}^{\infty}(1+r)^{-k}\left(\beta d r_{t+k+1}-\frac{r \lambda \varphi}{1+w \lambda \varphi} d \omega_{t+k}\right)$, the intertemporal substitution term from (A27). Then the stochastic discount factor and risk premium can be written as follows:

Proposition A1. To first order, evaluated at steady state,

$$
d m_{t+1}=-R^{a}(a, l ; \Theta) \beta d \hat{A}_{t+1}+\beta d \Phi_{t+1} .
$$

To second order, evaluated at steady state,

$$
\psi_{t}^{i}=R^{a}(a, l ; \Theta) \operatorname{Cov}_{t}\left(d r_{t+1}^{i}, d \hat{A}_{t+1}\right)-\operatorname{Cov}_{t}\left(d r_{t+1}^{i}, d \Phi_{t+1}\right) .
$$

Proof: Note first that $R^{a}(a, l ; \Theta)=\frac{\gamma}{c} \frac{r}{1+w \lambda \varphi}$. Substituting (A27) into (A26) yields (A28). Substituting (A28) into (A25) yields (A29). Finally, $\operatorname{Cov}(d x, d y)$ is accurate to second order when $d x$ and $d y$ are accurate to first order.

Equation (A29) characterizes the relationship between risk aversion and the risk premium on the asset. The first term in (A29) shows that $\psi_{t}^{i}$ increases locally linearly with $R^{a}$, by an amount that depends on the covariance between the asset return and the household's wealth, including nonfinancial wealth. This link between risk premia and risk aversion should not be too surprising: Propositions 1-2 described the risk premium for extremely simple, idiosyncratic gambles over household wealth, while Proposition A1 shows that the same coefficient also appears in the household's aversion to more general financial market gambles that may be correlated with aggregate variables such as interest rates, wages, and transfers.

The second term in (A29) corresponds to Merton's (1973) "changes in investment opportunities" in the ICAPM framework. Even if $R^{a}=0$ - that is, even if households are risk-neutral in a cross-sectional or CAPM sense - $\psi_{t}^{i}$ can be nonzero. This is because even a risk-neutral household can benefit from an asset that pays off well when the price of the household's total consumption bundle is low. An asset that pays off well when current and future wages are low (and hence leisure is cheap) or current and future interest rates are high (and hence future consumption is cheap) is preferable to an asset that pays off poorly in those situations. Even a risk-neutral household would be willing to pay a premium for such an asset-implying a lower $\psi_{t}^{i}$ - and this effect is captured by the second term in (A29).

The fact that households in the present paper face a consumption-leisure tradeoff as well as a currentvs.-future consumption tradeoff implies that the second term in (A29) is more general than just changes in the household's investment opportunities. Indeed, the second term in (A29) is better described as being due to "changes in purchasing opportunities." The decomposition in (A29) also suggests that $\psi_{t}^{i}$ is more accurately described as an "expected excess return" rather than a "risk premium" because only the first term in (A29) represents compensation to the household for bearing risk; the second term is not compensation for risk but rather reflects changes in the household's purchasing opportunities over time.

Finally, the decomposition (A29) can be written in terms of relative rather than absolute risk aversion using Definition 2: 
Corollary A1. In terms of relative risk aversion, the risk premium in (A29) can be written as:

$$
\psi_{t}^{i}=R^{c}(a, l ; \Theta) \operatorname{Cov} t\left(d r_{t+1}^{i}, \frac{d \hat{A}_{t+1}}{A}\right)-\operatorname{Cov} t\left(d r_{t+1}^{i}, d \Phi_{t+1}\right)
$$

where $A$ is as in Definition 2.

\section{Proof of Lemma A1}

Differentiating the household's Euler equation (13) and evaluating at steady state yields

$$
U^{\prime \prime}(c)\left(d c_{t}^{*}-E_{t} d c_{t+1}^{*}\right)=\beta U^{\prime}(c) E_{t} d r_{t+1} .
$$

It follows that, for each $k=1,2, \ldots$,

$$
E_{t} d c_{t+k}^{*}=d c_{t}^{*}+\frac{\beta c}{\gamma} E_{t} \sum_{i=1}^{k} d r_{t+i}
$$

Combining (3)-(4), differentiating, and evaluating at steady state yields

$$
E_{t} \sum_{k=0}^{\infty} \frac{1}{(1+r)^{k}}\left(d c_{t+k}^{*}-w d l_{t+k}^{*}-l d w_{t+k}-d d_{t+k}-a d r_{t+k}\right)=(1+r) d a_{t} .
$$

Differentiating the household's unemployment Euler equation (17) and evaluating at steady state yields

$$
\begin{aligned}
& \frac{V^{\prime \prime}(l+u)}{f(\Theta)}\left(d l_{\tau}^{*}+d u_{\tau}^{*}\right)-\frac{V^{\prime}(l+u)}{f(\Theta)^{2}} d f_{\tau}=\beta E_{\tau}\left[w U^{\prime \prime}(c) d c_{\tau+1}^{*}+U^{\prime}(c) d w_{\tau+1}\right. \\
& \left.+V^{\prime \prime}(l+u) \frac{1-s-f(\Theta)}{f(\Theta)}\left(d l_{\tau+1}^{*}+d u_{\tau+1}^{*}\right)-V^{\prime}(l+u) \frac{1-s}{f(\Theta)^{2}} d f_{\tau+1}\right]
\end{aligned}
$$

Rearranging (A34) gives

$$
\begin{aligned}
d l_{\tau}^{*}+d u_{\tau}^{*}=\beta(1-s- & f(\Theta)) E_{\tau}\left(d l_{\tau+1}^{*}+d u_{\tau+1}^{*}\right)-\frac{\gamma}{\chi} \frac{l+u}{c}(1-\beta(1-s-f(\Theta))) E_{\tau} d c_{\tau+1}^{*} \\
& +\frac{l+u}{\chi w}(1-\beta(1-s-f(\Theta))) E_{\tau} d w_{\tau+1}^{*}+\frac{l+u}{\chi f(\Theta)} d f_{\tau}-\beta \frac{l+u}{\chi} \frac{1-s}{f(\Theta)} E_{\tau} d f_{\tau+1},
\end{aligned}
$$

which, assuming $|s+f(\Theta)|<1$, can be solved forward to yield

$$
\begin{aligned}
d l_{\tau}^{*}+d u_{\tau}^{*}=-\frac{\gamma}{\chi} \frac{l+u}{c} & d c_{\tau}^{*}-\beta \frac{l+u}{\chi} E_{\tau} \sum_{k=1}^{\infty} \beta^{k-1}(1-s-f(\Theta))^{k-1} d r_{\tau+k} \\
& +\frac{l+u}{\chi}(1-\beta(1-s-f(\Theta))) E_{\tau} \sum_{k=1}^{\infty} \beta^{k-1}(1-s-f(\Theta))^{k-1} d w_{\tau+k} \\
& +\frac{l+u}{\chi f(\Theta)} d f_{\tau}-\beta \frac{l+u}{\chi} E_{\tau} \sum_{k=1}^{\infty} \beta^{k-1}(1-s-f(\Theta))^{k-1} d f_{\tau+k} .
\end{aligned}
$$

Note that, when current and future $r, w$, and $f(\Theta)$ do not change, (A36) reduces to (21). Define

$$
\begin{gathered}
d \omega_{\tau} \equiv-\beta E_{\tau} \sum_{k=1}^{\infty} \beta^{k-1}(1-s-f(\Theta))^{k-1} d r_{\tau+k}+(1-\beta(1-s-f(\Theta))) E_{\tau} \sum_{k=1}^{\infty} \beta^{k-1}(1-s-f(\Theta))^{k-1} d w_{\tau+k} \\
+\frac{1}{f(\Theta)} d f_{\tau}-\beta E_{\tau} \sum_{k=1}^{\infty} \beta^{k-1}(1-s-f(\Theta))^{k-1} d f_{\tau+k}
\end{gathered}
$$


Then

$$
d l_{\tau}^{*}+d u_{\tau}^{*}=-\frac{\gamma}{\chi} \frac{l+u}{c} d c_{\tau}^{*}-\frac{l+u}{\chi} d \omega_{\tau},
$$

so that (A38) corresponds to a standard intratemporal optimality condition between $l+u$ and $c$, and $d \omega_{\tau}$ represents the change in the present discounted value of the gains from searching for a job, analogous to $d w_{\tau}$ in a frictionless model.

Differentiating the transition equation (2) for labor and evaluating at steady state yields

$$
d l_{t+k}^{*}=(1-s-f(\Theta)) d l_{t+k-1}^{*}+f\left(\Theta_{t+k-1}\right)\left(d l_{t+k-1}^{*}+d u_{t+k-1}^{*}\right)+u d f_{t+k-1} .
$$

Solving backward to time $t$ gives

$$
d l_{t+k}^{*}=(1-s-f(\Theta))^{k} d l_{t}+\sum_{i=1}^{\infty}(1-s-f(\Theta))^{k-1-i}\left[f(\Theta)\left(d l_{t+i}^{*}+d u_{t+i}^{*}\right)+u d f_{t+i}\right] .
$$

Substituting (A38) into (A40) and taking expectations gives

$$
\begin{aligned}
E_{t} d l_{t+k}^{*}=(1-s- & f(\Theta))^{k} d l_{t}-\frac{\gamma}{\chi} \frac{l+u}{c} f(\Theta) \frac{1-(1-s-f(\Theta))^{k}}{s+f(\Theta)} d c_{t}^{*} \\
& +\frac{l+u}{\chi} f(\Theta) E_{t} \sum_{i=0}^{k-1}(1-s-f(\Theta))^{k-1-i} d \omega_{t+i}+u E_{t} \sum_{i=0}^{k-1}(1-s-f(\Theta))^{k-1-i} d f_{t+i} \\
& -\beta \frac{l+u}{\chi} \frac{f(\Theta)}{s+f(\Theta)} E_{t} \sum_{i=1}^{k-1}\left[1-(1-s-f(\Theta))^{k-i}\right] d r_{t+i} .
\end{aligned}
$$

Inserting (A41) into the budget constraint (A33) gives

$$
\begin{aligned}
\frac{1+r}{r}[1+ & \left.\frac{\gamma}{\chi} \frac{w l}{c} \frac{s+f(\Theta)}{r+s+f(\Theta)}\right] d c_{t}^{*}-\frac{1+r}{r+s+f(\Theta)} w d l_{t}-\frac{1}{r+s+f(\Theta)} E_{t} \sum_{k=0}^{\infty} \frac{1}{(1+r)^{k}} w u d f_{t+k} \\
& -\frac{1}{\chi} \frac{s+f(\Theta)}{r+s+f(\Theta)} E_{t} \sum_{k=0}^{\infty} \frac{1}{(1+r)^{k}} l d \omega_{t+k}+\frac{1+r}{r} \frac{\beta c}{\gamma}\left[1+\frac{\gamma}{\chi} \frac{w l}{c} \frac{s+f(\Theta)}{r+s+f(\Theta)}\right] E_{t} \sum_{k=1}^{\infty} \frac{1}{(1+r)^{k}} d r_{t+k} \\
& -E_{t} \sum_{k=0}^{\infty} \frac{1}{(1+r)^{k}}\left[l d w_{t+k}+d d_{t+k}+a d r_{t+k}\right]=(1+r) d a_{t}
\end{aligned}
$$

Solving for $d c_{t}^{*}$, using the definitions of $\lambda$ and $\varphi$, yields

$$
\begin{gathered}
d c_{t}^{*}=\frac{r}{1+r} \frac{1}{1+w \lambda \varphi}\left[(1+r) d a_{t}+(1+r) \frac{w}{r+s+f(\Theta)} d l_{t}\right. \\
\left.\quad+E_{t} \sum_{k=0}^{\infty} \frac{1}{(1+r)^{k}}\left(l d w_{t+k}+d d_{t+k}+a d r_{t+k}+\frac{w u}{r+s+f(\Theta)} d f_{t+k}\right)\right] \\
\quad-\frac{\beta c}{\gamma} E_{t} \sum_{k=1}^{\infty} \frac{1}{(1+r)^{k}} d r_{t+k}+\frac{r}{1+r} \frac{c}{\gamma} \frac{w \lambda \varphi}{1+w \lambda \varphi} E_{t} \sum_{k=0}^{\infty} \frac{1}{(1+r)^{k}} d \omega_{t+k} .
\end{gathered}
$$

\section{Expressions for Risk Aversion with Balanced Growth}

The results in the main text carry through essentially unchanged to the case of balanced growth. The corresponding expressions are collected here in Lemma A2, Proposition A2, and Corollary A2.

Along a balanced growth path, $x \in\{l, r, u\}$ satisfies $x_{t+k}=x_{t}$ for $k=1,2, \ldots$, and I drop the time subscript to denote the constant value. For $x \in\{a, c, w, d\}$, we have $x_{t+k}=G^{k} x_{t}$ for $k=1,2, \ldots$, for 
some $G \in(0,1+r)$, and we let $x_{t}^{b g}$ denote the balanced growth path value. I denote the balanced growth path value of $\Theta_{t}$ by $\Theta_{t}^{b g}$, although the elements of $\Theta$ may grow at different constant rates over time (or remain constant). The job-finding rate $f\left(\Theta_{t}^{b g}\right)$ must be constant along the balanced growth path because $f\left(\Theta_{t}^{b g}\right)=s l / u$, and I write this value as $f(\Theta)$. Additional details regarding balanced growth are provided in King, Plosser, and Rebelo (1988, 2002).

Lemma A2. Given Assumptions 1-6 and $7^{\prime}$, along the balanced growth path, $\partial c_{t+k}^{*} / \partial a_{t}=G^{k} \partial c_{t}^{*} / \partial a_{t}$, $k=1,2, \ldots$, and

$$
\frac{\partial c_{t}^{*}}{\partial a_{t}}=\frac{1+r-G}{1+\frac{\gamma}{\chi} \frac{w_{t}^{b g} l}{c_{t}^{b g}} \frac{s+f(\Theta)}{\left(\frac{1+r}{G}-1\right)+s+f(\Theta)}} .
$$

Proof: The household's Euler equation (13), evaluated along the (nonstochastic) balanced growth path, implies

$$
U^{\prime \prime}\left(c_{t}^{b g}\right)=\beta(1+r) U^{\prime \prime}\left(c_{t+1}^{b g}\right)=\beta(1+r) U^{\prime \prime}\left(G c_{t}^{b g}\right) .
$$

As in King, Plosser, and Rebelo (2002), assume that preferences $U$ are consistent with balanced growth for all initial asset stocks and wages in a neighborhood of $a_{t}^{b g}$ and $w_{t}^{b g}$, and hence for all initial values of $\left(c_{t}, l_{t}\right)$ in a neighborhood of $\left(c_{t}^{b g}, l\right)$. Thus, $(\mathrm{A} 45)$ can be differentiated to yield

$$
U^{\prime \prime}\left(c_{t}^{b g}\right)=\beta(1+r) G U^{\prime \prime}\left(G c_{t}^{b g}\right) .
$$

Differentiating (A45) with respect to $a_{t}$ yields

$$
U^{\prime \prime}\left(c_{t}^{b g}\right) \frac{\partial c_{t}^{*}}{\partial a_{t}}=\beta(1+r) U^{\prime \prime}\left(c_{t+1}^{b g}\right) \frac{\partial c_{t+1}^{*}}{\partial a_{t}} .
$$

Solving for $\partial c_{t+1}^{*} / \partial a_{t}$ and using (A46) yields $\partial c_{t+1}^{*} / \partial a_{t}=G \partial c_{t}^{*} / \partial a_{t}$.

Next, use the household's budget constraint (1)-(2) and the above to solve for $\partial c_{t}^{*} / \partial a_{t}$, following along the lines of (16)-(25).

The larger is $G$, the smaller is $\partial c_{t}^{*} / \partial a_{t}$, since the household chooses to absorb a greater fraction of asset shocks in future periods.

Proposition A2. Given Assumptions 1-6 and 7', absolute risk aversion satisfies

$$
R^{a}\left(a_{t}^{b g}, l ; \Theta_{t}^{b g}\right)=\frac{-\mathbb{V}_{11}\left(a_{t+1}^{b g}, l_{t+1}^{b g} ; \Theta_{t+1}^{b g}\right)}{\mathbb{V}_{1}\left(a_{t+1}^{b g}, l_{t+1}^{b g} ; \Theta_{t+1}^{b g}\right)}
$$

and

$$
R^{a}\left(a_{t}^{b g}, l ; \Theta_{t}^{b g}\right)=\frac{-U^{\prime \prime}\left(c_{t}^{b g}\right)}{U^{\prime}\left(c_{t}^{b g}\right)} \frac{\frac{1+r}{G}-1}{1+\frac{\gamma}{\chi} \frac{w_{t}^{b g} l}{c_{t}^{b g}} \frac{s+f(\Theta)}{\left(\frac{1+r}{G}-1\right)+s+f(\Theta)}}
$$

Proof: Proposition 1 implies (A48). Assumptions 1-6 imply (11)-(12). Substituting (11)-(12) and Lemma A2 into (A48) gives

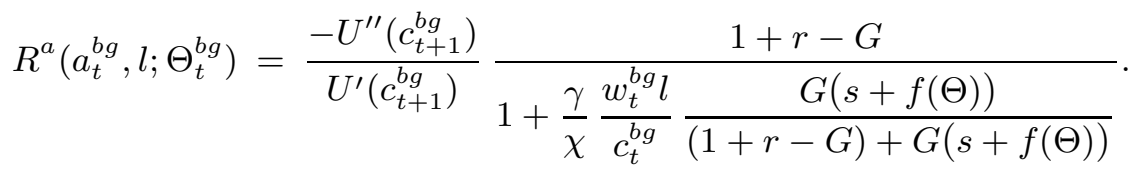


Applying the Euler equation (13) and (A45) completes the proof.

Note that (A50) agrees with Proposition 2 when $G=1$. The larger is $G$, the smaller is $R^{a}$, since larger $G$ implies greater household wealth and ability to absorb asset shocks.

Corollary A2. Given Assumptions 1-6 and $7^{\prime}$, relative risk aversion satisfies

$$
R^{c}\left(a_{t}^{b g}, l ; \Theta_{t}^{b g}\right)=\frac{\gamma}{1+\frac{\gamma}{\chi} \frac{w_{t}^{b g} l}{c_{t}^{b g}} \frac{s+f(\Theta)}{\left(\frac{1+r}{G}-1\right)+s+f(\Theta)}} .
$$

Proof: As in Definition 2, define wealth $A_{t}^{b g}$ in beginning- rather than end-of-period- $t$ units; this requires multiplying by $((1+r) / G)^{-1}$ rather than just $(1+r)^{-1}$. Then the present discounted value of consumption along the balanced growth path is given by $A_{t}^{b g}=c_{t}^{b g} /\left(\frac{1+r}{G}-1\right)$. Substituting these into Proposition A2 completes the proof.

Thus, the expressions for relative risk aversion are largely unchanged by balanced growth. The labor market flexibility index takes the form $\frac{s+f(\Theta)}{\left(\frac{1+r}{G}-1\right)+s+f(\Theta)}$ rather than $\frac{s+f(\Theta)}{r+s+f(\Theta)}$, which has the effect of decreasing the importance of $r$ and amplifying the importance of $s+f(\Theta)$ in the index, but other than that the expression is unchanged. 


\section{References}

Ai, Henguie, Mariano Max Croce, and Kai Li (2013). "Toward a Quantitative General Equilibrium Asset Pricing Model with Intangible Capital," Review of Financial Studies 26, 491-530.

Ai, Henguie, Mariano Max Croce, Anthony Diercks, And Kai Li (2018). "News Shocks and Production-Based Term Structure of Equity Returns," Review of Financial Studies 31, 2423-2467.

Alvarez, Fernando And Nancy Stokey (1998). "Dynamic Programming with Homogeneous Functions," Journal of Economic Theory 82, 167-189.

Andolfatto (1996). "Business Cycles and Labor-Market Search," American Economic Review 86, 112132.

Andreasen, Martin (2012a). "On the Effects of Rare Disasters and Uncertainty Shocks for Risk Premia in Nonlinear DSGE Models," Review of Economic Dynamics 15, 295-316.

Andreasen, Martin (2012b). "An Estimated DSGE Model: Explaining Variation in Nominal Term Premia, Real Term Premia, and Inflation Risk Premia," European Economic Review 56, 1656-1674.

Arrow, Kenneth (1965). "Aspects of the Theory of Risk-Bearing," Yrjö Jahnsson Lectures, in Essays in the Theory of Risk Bearing, ed. Arrow, Kenneth (Chicago: Markum, 1971).

Aruoba, S. Boragan, Jesús Fernández-Villaverde, and Juan Rubio-Ramírez (2006). "Comparing Solution Methods for Dynamic Equilibrium Economies," Journal of Economic Dynamics and Control 30, 2477-2508.

Backus, David, Bryan Routledge, and Stanley Zin (2008). "Asset Prices in Business Cycle Analysis," unpublished manuscript Tepper School of Business, Carnegie Mellon University.

Bansal, Ravi, and Amir Yaron (2004). "Risks for the Long Run: A Potential Resolution of AssetPricing Puzzles," Journal of Finance 59, 1481-1509.

Barillas, Francisco, Lars Hansen, and Thomas Sargent (2009). "Doubts or Variability?" Journal of Economic Theory 144, 2388-2418.

Barro, Robert (2006). "Rare Disasters and Asset Markets in the Twentieth Century," Quarterly Journal of Economics 121, 823-866.

Bodie, Zvi, Robert Merton, and William Samuelson (1992). "Labor Supply Flexibility and Portfolio Choice in a Life Cycle Model," Journal of Economic Dynamics and Control 16, 427-449.

Boldrin, Michele, Lawrence Christiano, and Jonas Fisher (1997). "Habit Persistence and Asset Returns in an Exchange Economy," Macroeconomic Dynamics 1, 312-332.

Boldrin, Michele, Lawrence Christiano, and Jonas Fisher (2001). "Habit Persistence, Asset Returns, and the Business Cycle," American Economic Review 91, 149-166.

Campbell, John (1999). "Asset Prices, Consumption, and the Business Cycle," in Handbook of Macroeconomics 1, ed. John Taylor and Michael Woodford (New York: Elsevier), 1231-1303.

CAmpbell, John, and John Cochrane (1999). "By Force of Habit: A Consumption-Based Explanation of Aggregate Stock Market Behavior," Journal of Political Economy 107, 205-251.

Cesarini, David, Erik Lindqvist, Matthew Notowidigdo, and Robert Ostling (2017). "The Effect of Wealth on Individual and Household Labor Supply: Evidence from Swedish Lotteries," American Economic Review 107, 3917-3946.

Cochrane, John. Asset Pricing (Princeton: Princeton University Press, 2005).

Cochrane, John, and Monika Piazzesi (2005). "Bond Risk Premia," American Economic Review 95, $138-160$. 
Coile, Courtney, and Paul Levine (2009). "The Market Crash and Mass Layoffs: How the Current Economic Crisis May Affect Retirement," NBER Working Paper 15395.

Constantinides, George (1990). "Habit Formation: A Resolution of the Equity Premium Puzzle," Journal of Political Economy 98, 519-543.

Constantinides, George, and Darrell Duffie (1996). "Asset Pricing with Heterogeneous Consumers," Journal of Political Economy 104, 219-240.

Cooper, Ilan, and Richard Priestley (2009). "Time-Varying Risk Premiums and the Output Gap" Review of Financial Studies 22, 2801-2833.

Coronado, Julia, And Maria Perozek (2003). "Wealth Effects and the Consumption of Leisure: Retirement Decisions During the Stock Market Boom of the 1990s," Federal Reserve Board Finance and Economics Discussion Series 2003-20.

Croce, Mariano Massimiliano (2014). "Long-Run Productivity Risk: A New Hope for ProductionBased Asset Pricing?" Journal of Monetary Economics 66, 13-31.

Del Negro, Marco, Marc Giannoni, and Frank Schorfheide (2015). "Inflation in the Great Recession and New Keynesian Models," American Economic Journal: Macroeconomics 7, 168-196.

Den Haan, Wouter, Garey Ramey, and Joel Watson (2000). "Job Destruction and Propagation of Shocks," American Economic Review 90, 482-498.

Dew-Becker, Ian (2014). "Bond Pricing with a Time-Varying Price of Risk in an Estimated MediumScale Bayesian DSGE Model," Journal of Money, Credit, and Banking 46, 837-888.

Elsby, Michael, Bart Hobijn, And Ayşegül Şahin (2013). "Unemployment Dynamics in the OECD," Review of Economics and Statistics 95, 530-548.

Epstein, Larry, Emmanuel Farhi, and Tomasz Strzalecki (2014). "How Much Would You Pay to Resolve Long-Run Risk?" American Economic Review 104, 2680-2697.

Epstein, Larry, and Stanley Zin (1989). "Substitution, Risk Aversion, and the Temporal Behavior of Consumption and Asset Returns: A Theoretical Framework," Econometrica 57, 937-969.

Fama, Eugene, and Kenneth French (1989). "Business Conditions and Expected Returns on Stocks and Bonds," Journal of Financial Economics 25, 23-49.

FArmer, Roger (1990). "RINCE Preferences," Quarterly Journal of Economics 105, 43-60.

Flavin, Marjorie, and Shinobu Nakagawa (2008). "A Model of Housing in the Presence of Adjustment Costs: A Structural Interpretation of Habit Persistence," American Economic Review 98, $474-495$.

García-Feijóo, Luis, and Randy Jorgensen (2010). "Can Operating Leverage Be the Cause of the Value Premium?" Financial Management Autumn, 1127-1153.

Gollier, Christian (2002). "What Does Theory Have to Say About Household Portfolios?" in Household Portfolios (MIT Press: Cambridge, MA), Guiso, Luigi, Michael Haliassos, and Tullio Jappelli (eds.), 27-54.

Gourio, Françols (2012). "Disaster Risk and Business Cycles," American Economic Review 102, 27342766.

Gourio, François (2013). "Credit Risk and Disaster Risk," American Economic Journal: Macroeconomics $5,1-34$.

Guiso, Luigi, Michael Haliassos, and Tullio Jappelli (2002). Household Portfolios (Mit Press: Cambridge, MA).

Guiso, Luigi, and Tullio Jappelli (2002). "Household Portfolios in Italy," in Household Portfolios (MIT Press: Cambridge, MA), Guiso, Luigi, Michael Haliassos, and Tullio Jappelli (eds.), 251-289. 
Guiso, Luigi, Paola Sapienza, and Luigi Zingales (2017). "Time Varying Risk Aversion," Journal of Financial Economics forthcoming.

Hall, Robert (2005). "Employment Fluctuations with Equilibrium Wage Stickiness," American Economic Review 95, 50-65.

Hall, Robert (2017). "High Discounts and High Unemployment," American Economic Review 107, $305-330$.

Hobijn, Bart, And Ayşegül ŞAhin (2007). "Job-Finding and Separation Rates in the OECD," Federal Reserve Bank of New York Staff Report 298.

Imbens, Guido, Donald Rubin, and Bruce Sacerdote (2001). "Estimating the Effect of Unearned Income on Labor Earnings, Savings, and Consumption: Evidence from a Survey of Lottery Players," American Economic Review 91, 778-794.

Jermann, Urban (1998). "Asset Pricing in Production Economies," Journal of Monetary Economics 41, $257-275$.

Kihlstrom, Richard, and Leonard Mirman (1974). "Risk Aversion with Many Commodities," Journal of Economic Theory 8, 361-388.

Kihlstrom, Richard, and Leonard Mirman (1981). "Constant, Increasing, and Decreasing Risk Aversion with Many Commodities," Review of Economic Studies 48, 271-280.

Killingsworth, Mark, and James Heckman (1986). "Female Labor Supply: A Survey," Handbook of Labor Economics 1, 103-204.

King, Robert, Charles Plosser, and Sergio Rebelo (1988). "Production, Growth, and Business Cycles: I. The Basic Neoclassical Model," Journal of Monetary Economics 21, 195-232.

King, Robert, Charles Plosser, and Sergio Rebelo (2002). "Production, Growth, and Business Cycles: Technical Appendix," Computational Economics 20, 87-116.

Kung, Howard (2015). "Macroeconomic Linkages between Monetary Policy and the Term Structure of Interest Rates," Journal of Financial Economics 115, 42-57.

Lettau, Martin, and Sydney Ludvigson (2010). "Measuring and Modeling Variation in the RiskReturn Trade-off," Handbook of Financial Econometrics 1, 617-690.

Merton, Robert (1973). "An Intertemporal Capital Asset Pricing Model," Econometrica 41, 867-887.

Merz, Monika (1995). "Search in the Labor Market and the Real Business Cycle," Journal of Monetary Economics 36, 269-300.

Michaillat, Pascal (2012). "Do Matching Frictions Explain Unemployment? Not in Bad Times," American Economic Review 102, 1721-1750.

Mortensen, Dale, and Christopher Pissarides (1994). "Job Creation and Job Destruction in the Theory of Unemployment," Review of Economic Studies 61, 397-415.

Palomino, Francisco (2012). "Bond Risk Premiums and Optimal Monetary Policy," Review of Economic Dynamics 15, 19-40.

Pencavel, John (1986). "Labor Supply of Men: A Survey," Handbook of Labor Economics 1, 3-102.

Piazzesi, Monika, And Eric Swanson (2008). "Futures Prices as Risk-Adjusted Forecasts of Monetary Policy," Journal of Monetary Economics 55, 677-691.

Pratt, John (1964). "Risk Aversion in the Small and in the Large," Econometrica 32, 122-136.

Rincón-Zapatero, Juan, and Carlos Rodríguez-Palmero (2003). "Existence and Uniqueness of Solutions to the Bellman Equation in the Unbounded Case," Econometrica 71, 1519-1555. 
Rouwenhorst, K. Geert (1995). "Asset Pricing Implications of Equilibrium Business Cycle Models," in Frontiers of Business Cycle Research, ed. Cooley, Thomas (Princeton: Princeton University Press).

Rudebusch, Glenn, and Eric Swanson (2008). "Examining the Bond Premium Puzzle with a DSGE Model," Journal of Monetary Economics 55, 111-126.

Rudebusch, Glenn, and Eric Swanson (2012). "The Bond Premium in a DSGE Model with Long-Run Real and Nominal Risks," American Economic Journal: Macroeconomics 4, 105-143.

Santos, Manuel (1991). "Smoothness of the Policy Function in Discrete Time Economic Models," Econometrica 59, 1365-1382.

SChmidt, LAWrence (2016). "Climbing and Falling Off the Ladder: Asset Pricing Implications of Labor Market Event Risk," unpublished manuscript Sloan School of Management.

Shimer, Robert (2010). Labor Markets and Business Cycles (Princeton: Princeton University Press).

Shimer, Robert (2012). "Reassessing the Ins and Outs of Unemployment," Review of Economic Dynamics $15,127-148$.

Stiglitz, Joseph (1969). "Behavior Towards Risk with Many Commodities," Econometrica 37, 660-667.

Smets, Frank, And Rafael Wouters (2007). "Shocks and Frictions in US Business Cycles: A Bayesian DSGE Approach," American Economic Review 97, 586-606.

Stokey, Nancy, And Robert Lucas, with Edward Prescott (1989). Recursive Methods in Economic Dynamics (Chicago: University of Chicago Press).

Swanson, Eric (2009). "Risk Aversion, the Labor Margin, and Asset Pricing in DSGE Models," Federal Reserve Bank of San Francisco Working Paper 2009-26.

Swanson, Eric (2012). "Risk Aversion and the Labor Margin in Dynamic Equilibrium Models," American Economic Review 102, 1663-1691.

Swanson, Eric (2018). "Risk Aversion, Risk Premia, and the Labor Margin with Generalized Recursive Preferences," Review of Economic Dynamics 28, 290-321.

Swanson, Eric (2019). "A Macroeconomic Model of Equities and Real, Nominal, and Defaultable Debt," unpublished manuscript University of California, Irvine.

Swanson, Eric, Gary Anderson, and Andrew Levin (2006). "Higher-Order Perturbation Solutions to Dynamic, Discrete-Time Rational Expectations Models," Federal Reserve Bank of San Francisco Working Paper 2006-01.

Tallarini, Thomas (2000). "Risk-Sensitive Business Cycles," Journal of Monetary Economics 45, 507532.

Trigari, Antonella (2009). "Equilibrium Unemployment, Job Flows, and Inflation Dynamics," Journal of Money, Credit, and Banking 41, 1-33.

Uhlig, Harald (2007). "Leisure, Growth, and Long-Run Risk," unpublished manuscript University of Chicago.

Van Binsbergen, Jules, Jesús Fernández-Villaverde, Ralph Koijen, and Juan Rubio-Ramírez (2012). "The Term Structure of Interest Rates in a DSGE Model with Recursive Preferences," Journal of Monetary Economics 59, 634-648.

Weil, Phillipe (1989). "The Equity Premium Puzzle and the Risk-Free Rate Puzzle," Journal of Monetary Economics 24, 401-421.

Ynesta, IsABelle (2008). "Households' Wealth Composition Across OECD Countries and Financial Risks Borne by Households," OECD Financial Market Trends . 